\title{
Frequency dependent cross-shore suspended sediment transport. 2. A barred shoreface
}

\author{
Philip D. Osborne and Brian Greenwood \\ Scarborough College Coastal Research Group, University of Toronto, Scarborough, Ont. MIC 1A4, Canada \\ (Received June 14, 1991; revision accepted December 5, 1991)
}

\begin{abstract}
Osborne, P.D. and Greenwood, B., 1992. Frequency dependent cross-shore suspended sediment transport. 2. A barred shoreface. Mar. Geol., 106: 25-51.
\end{abstract}

Field measurements of the local time-varying suspended sediment flux across a barred shoreface demonstrate that sediment transport is a respons $€$ to high frequency wind wave oscillatory currents, low frequency waves and mean flows. The relative importance of the various transport components varies spatially and temporally in association with variability in the incident wave energy. In contrast to the non-barred shoreface, where variations were strongly depth-dependent, sediment transport across the barred shoreface is constrained by position with respect to the bars.

On the lakeward slope of the bar, wind-wave oscillatory currents induce large rates of onshore transport near the bed; low frequency oscillatory currents $(<0.05 \mathrm{~Hz})$ in this region are driven by the group-forced, bound long wave and produce an offshore transport, often equal in magnitude to that induced by the wind waves. The sediment transport attributable to mean currents near the bed is always offshore, resulting in a net offshore sediment flux across the slope. On the bar crest, net sediment transport is seen to be close to zero, owing to a balance between the offshore mean transport and the onshore net oscillatory transport (resulting from interaction between both high and low frequency waves).

Landward of the bar crest and in the trough, sediment transport by wind waves decreases owing to dissipation of energy during wave breaking. In contrast, the contribution to suspended sediment transport by low frequency waves increases relatively, and furthermore this transport is now predominantly landward. This transport is probably associated with the release of the group-bound long wave as a free wave and the associated landward sediment flux approximates the offshore transport induced by the mean currents.

Local variability in the frequency dependent transport, both in terms of magnitude and direction is closely related to the bedforms present and their variation in response to increasing and decreasing wave energy. Specifically, the oscillatory transport attributable to wind-wave frequencies is predominantly onshore in the presence of steep vortex ripples, but is directed offshore as the flow regime shifts to lower amplitude post-vortex ripples.

\section{Introduction}

Recent field measurements of suspended sediment concentrations and the associated velocity fields under shoaling and breaking waves in the nearshore zone have revealed the strong frequency dependent character of the sediment transport process (Huntley and Hanes, 1987; Beach and Sternberg, 1988; Osborne et al., 1990; Greenwood

Correspondence to: B. Greenwood, University of Toronto, Scarborough College Coastal Res. Gr., Department of Geography, 1265 Military Trail, Scarborough, Ont. M1C IA4, Canada. et al., 1991a,b; etc.). In a previous paper, Osborne and Greenwood (1992c, this issue)-hereafter OG92-demonstrated a direct relationship between the local sediment balance constraining the morphodynamics of a non-barred (planar) shoreface and variations in the frequencydependent, cross-shore suspended sediment transport both spatially and temporally, over a complete storm cycle. In this paper, field measurements demonstrate the relationships that exist between the local hydrodynamics, the cross-shore suspended sediment transport and the morphodynamics of a barred shoreface. Specific aims of this 
paper are: (1) to identify the important cross-shore suspended sediment transport mechanisms under a variety of shoreface boundary conditions (including shoaling waves, breaking waves, surf bores and various local bed slopes, bedforms, grain sizes etc.); (2) to define the relative importance of these transport mechanisms to the local net cross-shore flux of suspended sediment; (3) to relate the local net cross-shore fluxes of suspended sediment to large scale morphological changes, and hence the maintenance of a barred form; and (4) to document any similarities or differences in sediment transport between barred and non-barred environments.

\section{Location of study}

Data were collected from a lacustrine barred shoreface during experiments conducted as part of the C-COAST programme (Greenwood et al., 1990) at Bluewater Beach, Ontario, Canada (Fig. 1). The study site is essentially tideless, with water level shifts restricted in the short-term to

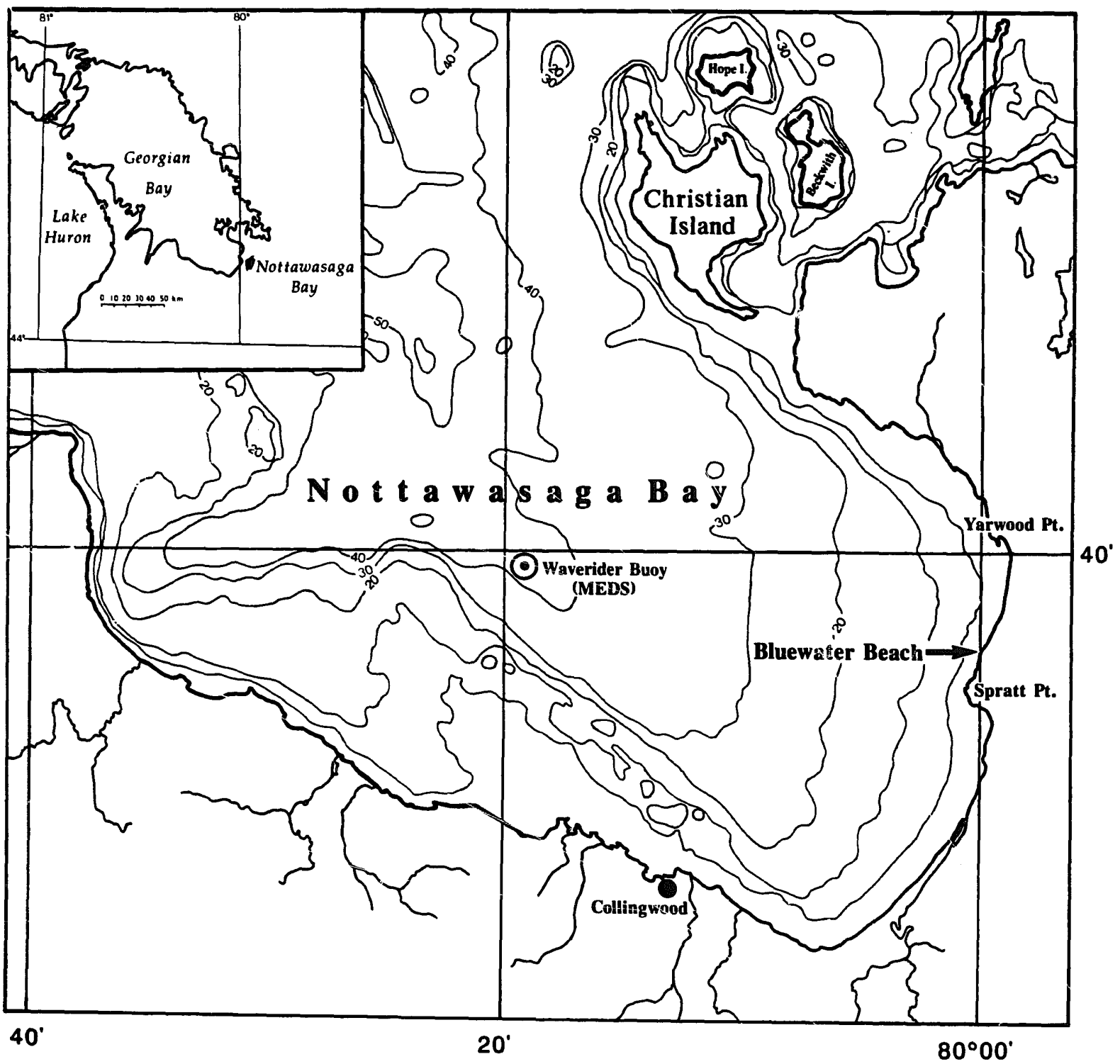

Fig. 1. Field site, Bluewater Beach, Nottawasaga Bay, Ontario, Canada. Note: contours are in fathoms; location of the MEDS Waverider Buoy is indicated. 
wind and wave set-up and seiche effects; equally large seasonal and long-term changes are climaticaily controlled. Low-to-moderate wave energy is generated over discrete time intervals during the passage of meteorological depressions. With a restricted fetch (maximum effective fetch $\approx 84 \mathrm{~km}$ from the WNW), wind forcing of short period $(<7-8$ s) waves is continuous under most wave states and true swell is absent.

Bluewater Beach is typical of the sandy shorefaces in Nottawasaga Bay, exhibiting a welldeveloped bar-trough system during the ice-free year (Greenwood, 1987). In June 1988, three sinuous-to-crescentic bars were present with crests approximately 35,63 and $150 \mathrm{~m}$ offshore on a mean nearshore slope $\approx 0.015$ (Fig. 2) in fine-tomedium, moderately-to-very well-sorted, negatively skewed sands (Table 1). In contrast, a single, sinuous-to-crescentic bar was located approximately $70 \mathrm{~m}$ offshore the previous year (Fig. 2).

\section{Instrumentation and measurements}

The sensors used to measure waves, currents and suspended sediment concentrations have been described previously, as have the calibration procedures, sampling schemes and data processing techniques (OG92). It is sufficient to note that six sediment transport monitoring stations were deployed along a shore-normal transect at 25, 55,

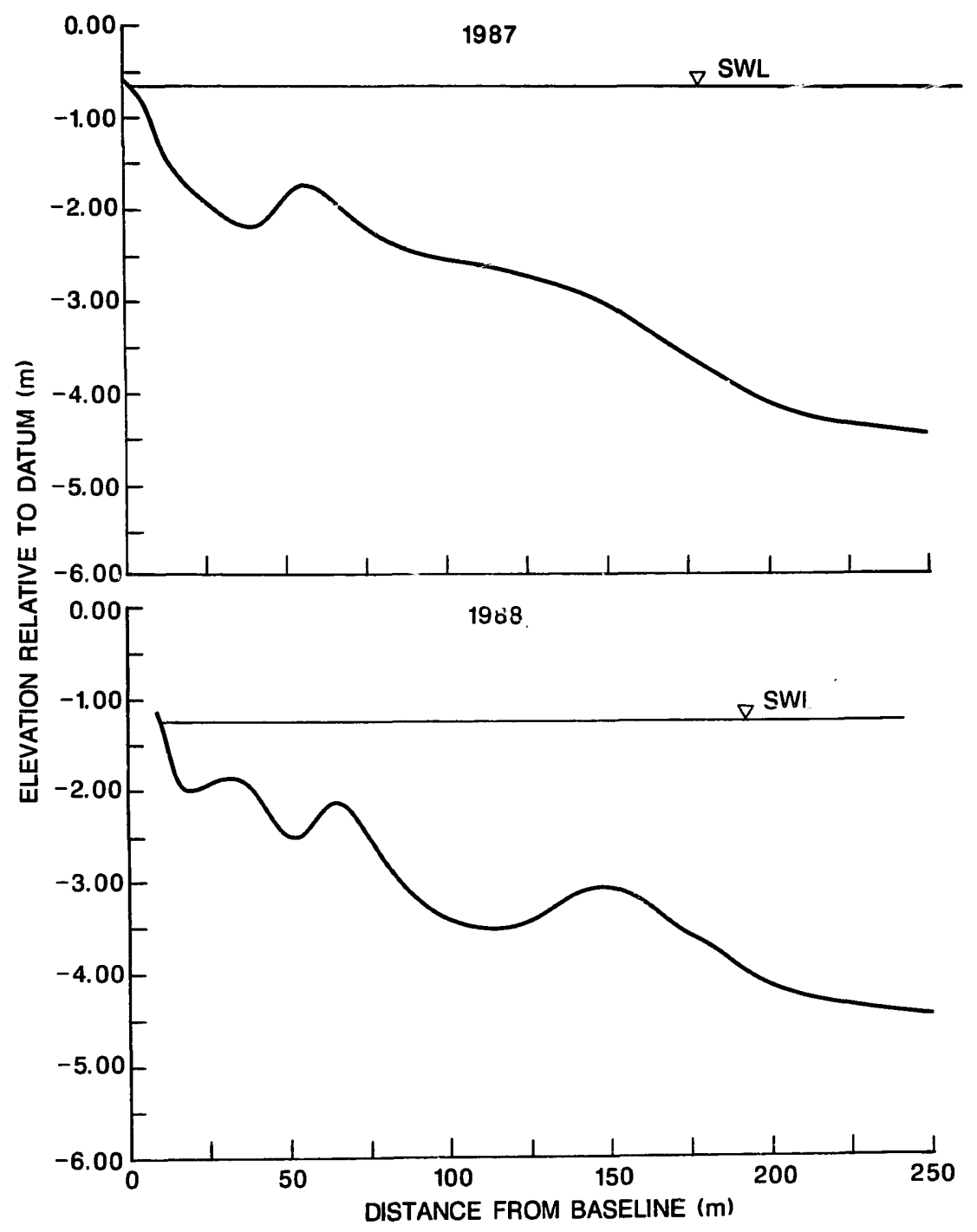

Fig. 2. Shoreface profiles, Bluewater Beach, 1987 and 1988. 


\section{TABLE 1}

Grain size characteristics of the shoreface at Bluewater Beach. Note: samples were dry-sieved at 1/4 $\Phi$ intervals and statistics computed by the method of moments

\begin{tabular}{|c|c|c|c|c|}
\hline \multirow{2}{*}{$\begin{array}{l}\text { Location } \\
\text { (m) }\end{array}$} & \multicolumn{2}{|c|}{ Mean size } & \multirow{2}{*}{$\begin{array}{l}\text { Sorting } \\
\Phi\end{array}$} & \multirow{2}{*}{$\begin{array}{l}\text { Skewness } \\
\Phi\end{array}$} \\
\hline & $\Phi$ & $\mathrm{mm}$ & & \\
\hline 150 & 2.63 & 0.16 & 0.55 & -1.34 \\
\hline 110 & 2.11 & 0.23 & 0.73 & -0.49 \\
\hline 85 & 2.93 & 0.13 & 0.33 & -0.45 \\
\hline 65 & 2.44 & 0.18 & 0.42 & -0.49 \\
\hline 55 & 2.07 & 0.24 & 0.68 & -1.85 \\
\hline
\end{tabular}

$63,85,110$ and $150 \mathrm{~m}$ offshore from a fixed baseline (Fig. 3). Each transport station consisted of: (1) a vertical array of two collocated optical backscatterance suspended solids sensors (Model OBS-1P: Downing et al., 1981; D and A Instruments and Engineering, 1988; nominal elevations of $z \approx 0.04$ and $0.10 \mathrm{~m} ;(2)$ two biaxial electromagnetic current meters (Marsh-McBirney, Model OEM 512; nominal elevations of $z \approx 0.10$ and 0.50 $\mathrm{m}$; and (3) a single pressure transducer (nominal elevation of $z \approx 0.20 \mathrm{~m}$ ). A vertical array of 3 electromagnetic current meters (nominal elevations of $z \approx 0.10,0.25$ and $0.50 \mathrm{~m}$ ) was located $130 \mathrm{~m}$ offshore; single current meters $(z \approx 0.20 \mathrm{~m})$ and pressure transducers $(z \approx 0.10 \mathrm{~m})$ were collocated 180 and $230 \mathrm{~m}$ offshore respectively (Fig. 3). Local wind speed and direction were recorded continuously using a WindMonitor (Model 05103, R.M. Young Co.) at $10 \mathrm{~m}$ elevation at the back of the beach and stored as 10 minute averages.

An underwater video camera was deployed at the $85 \mathrm{~m}$ station to record the bedforms and sediment suspension events during daylight hours. Similar observations were made at the remaining stations by SCUBA divers. Large-scale morphological changes were monitored by standard survey procedures (OG92). Pre- and post-storm measurements from two arrays of depth-of-activity rods (5 and $10 \mathrm{~m}$ north of the instrument transectFig. 3) provided greater morphological resolution and also limits to the displacement of sensors above the bed during the storm. Estimates of the depth-of-activity, the time-integrated total (ITVF) and the time-integrated net $(I N V F)$ sediment vol-

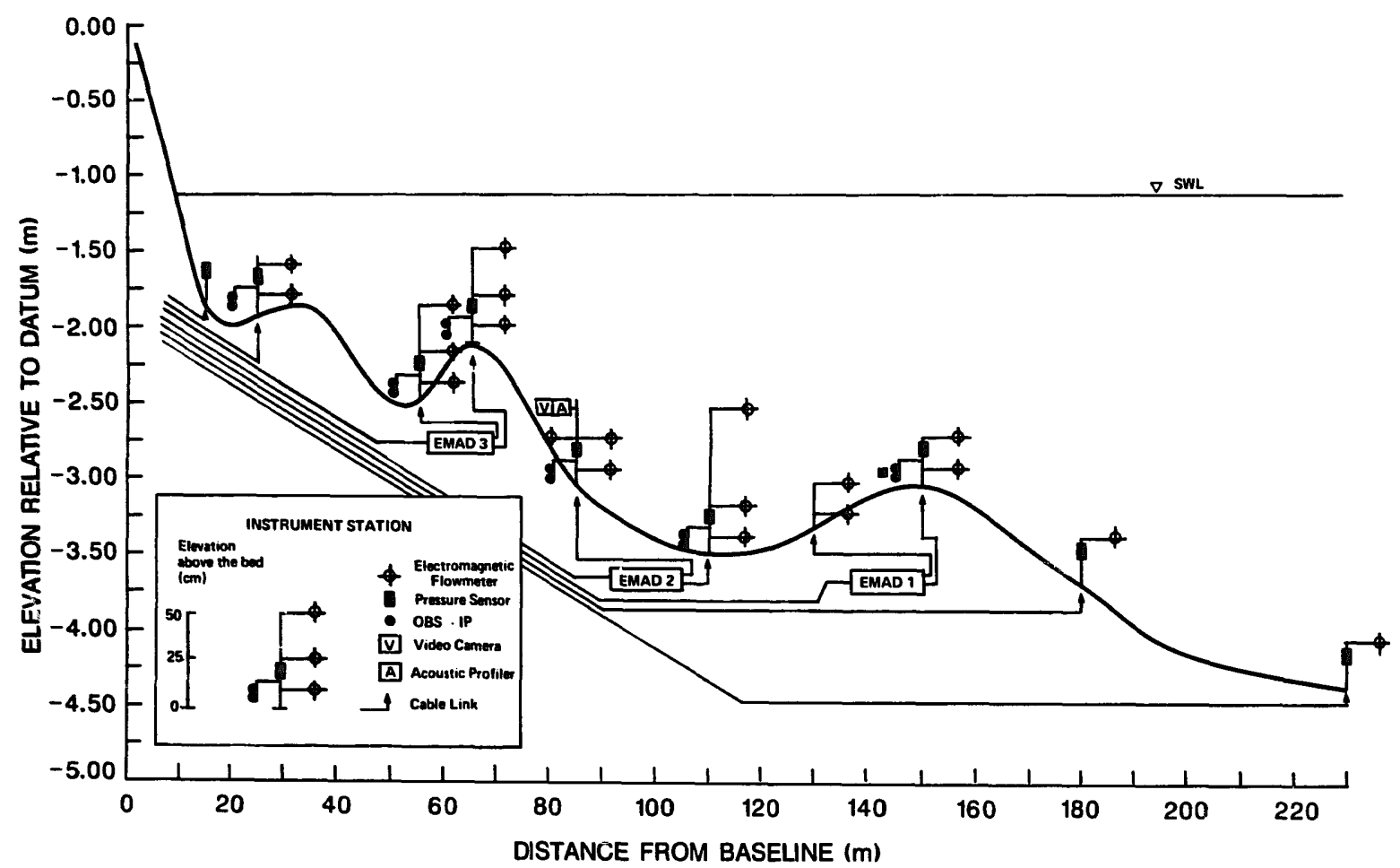

Fig. 3. Shoreface profile and sensor deployment. Note: EMAD 1-3 are underwater analogue-to-digital converters and digital transmission packages; they also distribute power to the sensors. 
ume fluxes were also calculated to examine details of the sediment balance as in (OG92).

\section{Sediment transport calculations and analytical procedures}

Calculation of the local net, mean and oscillatory transport rates for suspended sediment from the velocity and sediment concentration vectors was identical to that in OG92, namely:

$$
\begin{aligned}
& <u c\rangle_{\text {net }}=\frac{1}{n} \sum u c \\
& \langle u c\rangle_{\text {net }}=\left\langle u c>_{\text {mean }}+\langle u c\rangle_{\text {osc }}\right. \\
& \langle u c\rangle_{\text {mean }}=\frac{1}{n} \sum u \cdot \frac{1}{n} \sum c \\
& \langle u c\rangle_{\text {osc }}=\frac{\Delta f}{f_{c}} \sum C_{\text {uc }}(f)
\end{aligned}
$$

where $u=$ instantaneous cross-shore velocity (m $\left.\mathrm{s}^{-1}\right) ; c=$ instantaneous suspended sediment concentration $\left(\mathrm{kg} \mathrm{m}^{-3}\right) ; n=$ number of observations; $C_{\mathrm{uc}}=$ co-spectrum of velocity and concentration; $f=$ frequency $(\mathrm{Hz}) ; \Delta f=$ bandwidth for spectral estimates; and $f_{\mathrm{c}}=$ frequency range.

Statistics used to describe the waves (e.g. the variance of the water surface elevation), the crossshore velocities (e.g. the time-averaged mean, standard deviation and skewness) and the suspended sediment concentrations (e.g. the time-averaged mean and variance) were computed using the BMDP 2D Statistical Analysis Program (Dixon, 1985). Standard deviations of the water surface elevation and cross-shore, horizontal velocity records were used to estimate average and maximum values for both the wave heights and oscillatory currents using accepted converitions. Variance spectra, cross-spectra and cross-correlations were computed using the BMDP 1T and 2T Time Series Analysis Programs (Dixon, 1985). All time-series were truncated to approximately 17 minutes prior to analysis to satisfy assumptions of record stationarity in this rapidly changing environment, while at the same time retaining a sufficient number of points (4096) to maintain a high degree of statistical confidence especially in the Fourier transformations. In the latter case data were also demeaned and spectral estimates obtained every $0.01 \mathrm{~Hz}$ from 0.0 to $2.0 \mathrm{~Hz}$ with a resolution bandwidth of $0.03 \mathrm{~Hz}$ and 70 degrees of freedom.

\section{Storm event summary}

A single storm on June 16,1988 , provides the focus for this paper, although reference is made to other wave events for specific purposes. During the June 16 storm, deep water $(92.4 \mathrm{~m})$ significant wave heights (MEDS buoy-Fig. 1) ranged from $0.14 \mathrm{~m}$ with a peak period of $2.25 \mathrm{~s}(0250 \mathrm{~h})$ to $0.92 \mathrm{~m}$ with a peak period of $5.00 \mathrm{~s}(1620 \mathrm{~h})$. Figure 4 illustrates the wind speed and direction and the significant height $\left(H_{\mathrm{s}}\right)$ and peak wave period $\left(T_{\mathrm{pk}}\right)$ in the nearshore zone; also illustrated are the cross-shore oscillatory velocity $\left(u_{\mathrm{s}}\right)$ and velocity skewness $\left(u_{\text {sk }}\right)$ and the mean cross-shore $(u)$ and mean shore-parallel $(v)$ currents measured within the trough of the second bar. Winds were oriented close to the maximum fetch direction throughout the storm and wave height and period lagged the wind speed by 0.5 to $1 \mathrm{~h}$. Waves reached maxima in shallow water at $0430 \mathrm{~h}$ and 1500 in following wind maxima at $0330 \mathrm{~h}$ and $1430 \mathrm{~h}$. Wave period increased from $2.5 \mathrm{~s}$ early in the storm to a maximum of approximately $4 \mathrm{~s}$ at the storm peak when breaking wave heights exceeded $1.00 \mathrm{~m}$. Oscillatory currents of approximately $1.00 \mathrm{~m} \mathrm{~s}^{-1}$ and mean cross-shore currents of approximately $0.10 \mathrm{~m} \mathrm{~s}^{-1}$ were measured under the breaking waves. Shore-parallel currents were directed southwards under the northwesterly wave approach with time-averaged speeds not exceeding $0.40 \mathrm{~m} \mathrm{~s}^{-1}$. Sediment was re-suspended throughout the June 16 storm across all three bar-trough systems and transport over post-vortex ripples was recorded continuously by the video camera for a period of about six hours at the $85 \mathrm{~m}$ station (water depth, $h \approx 1.8 \mathrm{~m}$ ). Flat bed with sheet flow was observed on the crest of the second bar $(63 \mathrm{~m}$ station, $h \approx 0.5 \mathrm{~m}$ ) during the peak of the storm.

\section{Wave-induced suspended sediment transport}

Bar topography introduces significantly larger and more variable gradients in local shoreface slopes than those associated with non-barred pro- 

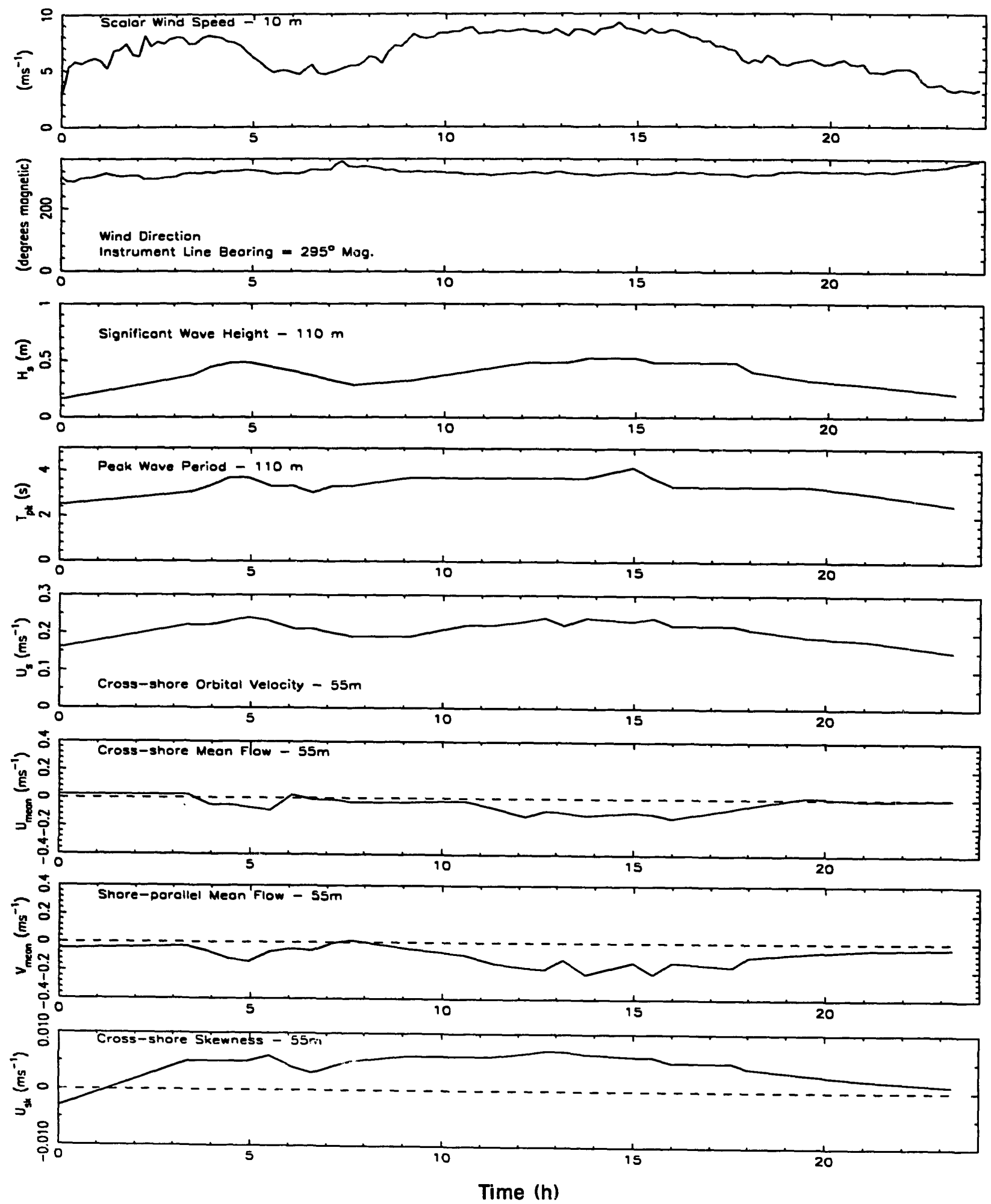

Fig. 4. Temporal variability in local wind speed and direction, significant wave height $\left(H_{\mathrm{s}}\right)$ and peak period $\left(T_{\mathrm{pk}}\right)$ at the $110 \mathrm{~m}$ station, average orbital current speed $\left(u_{\mathrm{s}}\right)$, mean cross-shore $\left(u_{\text {mean }}\right)$ and alongshore $\left(v_{\text {mean }}\right)$ velocity and cross-shore velocity skewness $\left(u_{\mathrm{sk}}\right)$ at the $55 \mathrm{~m}$ station throughout the June $16 \mathrm{storm}$. 
files; this variability results in larger spatial gradients in the fluid dynamics associated with the propagating waves (Greenwood and Sherman, 1984, 1986a; Greenwood and Osborne, 1991a). Furthermore, in fetch-restricted environments temporal gradients in the fluid dynamics are large, since incident wave fields evolve rapidly. Similarly large gradients in sediment dynamics might therefore be expected at Bluewater Beach. A basic understanding of both sediment and bar dynamics will therefore be achieved by examining the suspended sediment transport response to changes in the wave height-to-water depth ratio through space and time (as in OG92). The constraints imposed by bedforms on suspended sediment transport rates will also be considered (as in Osborne and Greenwood, 1992a).

Measurements from the second bar-trough system $(85,63$ and $55 \mathrm{~m}$ stations-Fig. 3) are emphasized in the following sections to illustrate interactions between the nearshore hydrodynamics, suspended sediment transport and bar morphodynamics over the full range of incident wave conditions. Data from the $85 \mathrm{~m}$ station will be used to describe the suspended sediment flux associated with varying waves and bedforms, but where the grain size distribution at the bed remains constant. Sediment flux is computed using the velocity vector at $z \approx 0.10 \mathrm{~m}$ and the sediment concentration vector at $z \approx 0.04 \mathrm{~m}$.

Non-breaking waves $\left(H_{\mathrm{s}} / h<0.2\right)$

Under non-breaking shoaling waves, kinetic energy is distributed over a wide range of frequencies but with a significant peak corresponding to the incident wind-wave frequency $(0.33 \mathrm{~Hz}$, Fig. 5a). This peak is truncated sharply at its lower frequency limit, with spectral variance reduced by more than two orders of magnitude between 0.33 and $0.22 \mathrm{~Hz}$, while a similar reduction in energy is spread over a frequency band of $0.39 \mathrm{~Hz}$ at the highest frequencies. A small but statistically significant peak of kinetic energy can be identified in the infragravity band (e.g. centred around $0.05 \mathrm{~Hz}$ $(20 \mathrm{~s})$ in Fig. 5a). Such a pattern was characteristic throughout the June 16 storm (Fig. 6).

In contrast, most of the variance in the sus- pended sediment concentration spectra (Figs. 5a and 6) is distributed at frequencies less than $0.10 \mathrm{~Hz}(10 \mathrm{~s})$. Broad peaks at the wind-wave frequency $(0.25-0.40 \mathrm{~Hz})$ and at the frequency of the first harmonic of the primary wave $(0.5$ $0.75 \mathrm{~Hz}$ ) can occasionally be detected (Figs. 5a and 6a). In these examples, the lack of corresponding peaks at the first harmonic in the velocity spectra indicates that sediment concentrations responded twice during each individual wind-wave cycle (i.e. with both the onshore and offshore components of flow).

Under shoaling waves, the co-spectra of velocity and sediment concentration exhibit peaks corresponding to those at both the incident and infragravity band frequencies in the cross-shore velocity spectrum (Figs. 5b and 6). Relatively large positive peaks (onshore transport) coincide with the incident wave band $(\approx 0.20-0.40 \mathrm{~Hz})$; significantly smaller, negative peaks (offshore transport) were associated with the infragravity band $(0.01-$ $0.04 \mathrm{~Hz}$ ).

In an attempt to identify the low frequency oscillations, the time series of the cross-shore velocities were subjected to a simple band-pass filter (centred at $0.05 \mathrm{~Hz}$, bandwidth $0.05 \mathrm{~Hz}$ ). The low frequency modulation of the cross-shore velocity (Fig. 5c) has all the characteristics of a groupbound forced long wave (Longuet-Higgins and Stewart, 1962). Grouping of larger amplitude waves increases the local radiation stress gradients and the resultant set-down of the mean water surface, giving rise to the troughs of this long wave. In the time series illustrated (Fig. 5c), eight cycles of the long wave are recognizable, suggesting a frequency of $0.04 \mathrm{~Hz}$ which is coincident with the low frequency spectral peak in the cross-shore velocities (Fig. 5a). As a consequence of the group forcing, the troughs of the long wave coincide with the largest sediment concentrations induced by resuspension resulting from the larger bottom shear stresses associated with the larger waves in the group (Fig. 5d). Band pass filtering of the sediment concentration time series revealed a significant concentration cycle with the same frequency $(0.04 \mathrm{~Hz})$. The temporal coherence between the troughs of the group bound forced long wave and large sediment concentrations explains, at least in 


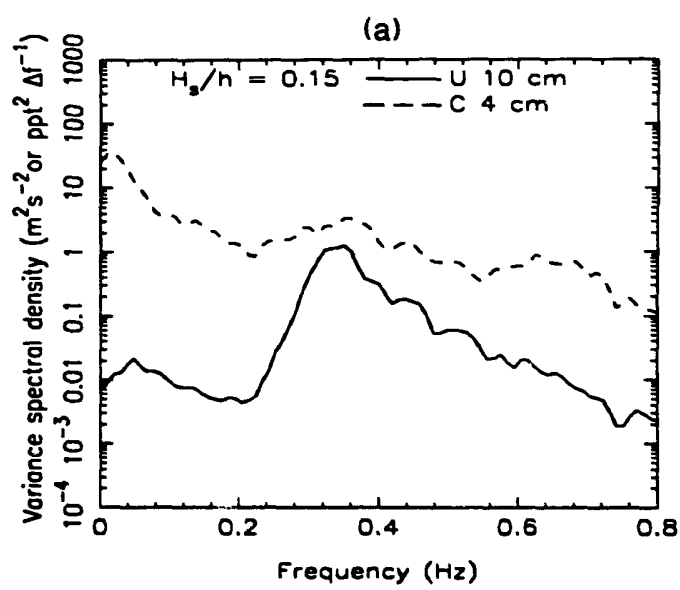

(b)

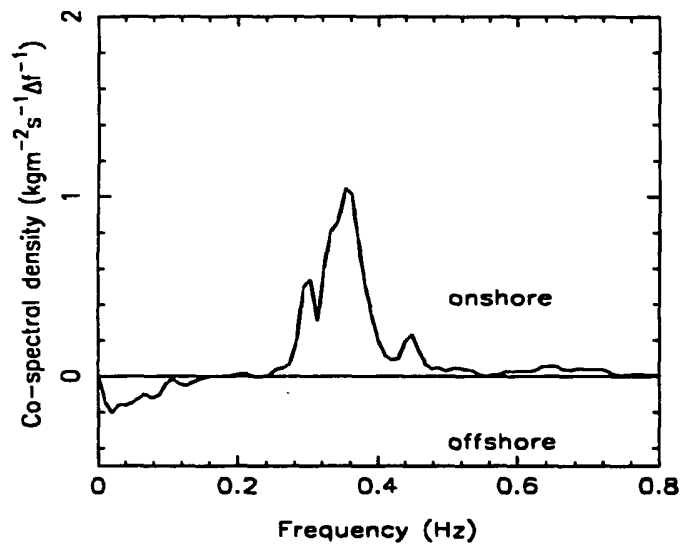

(c)

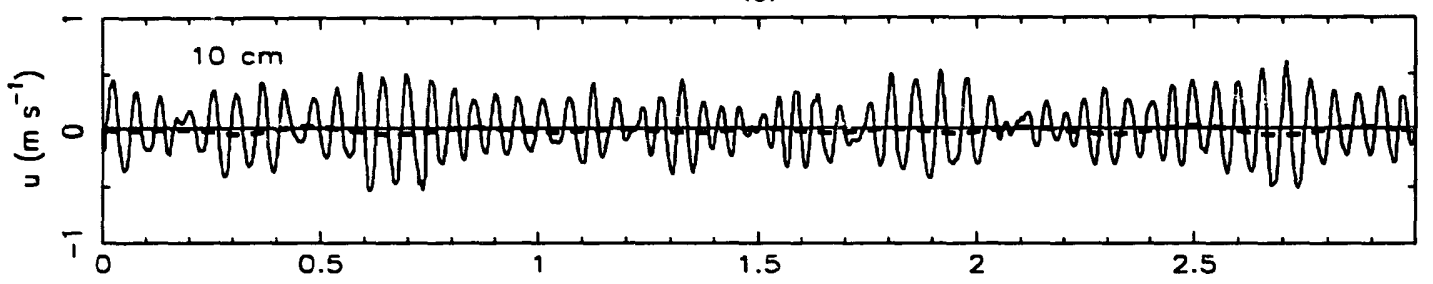

(d)

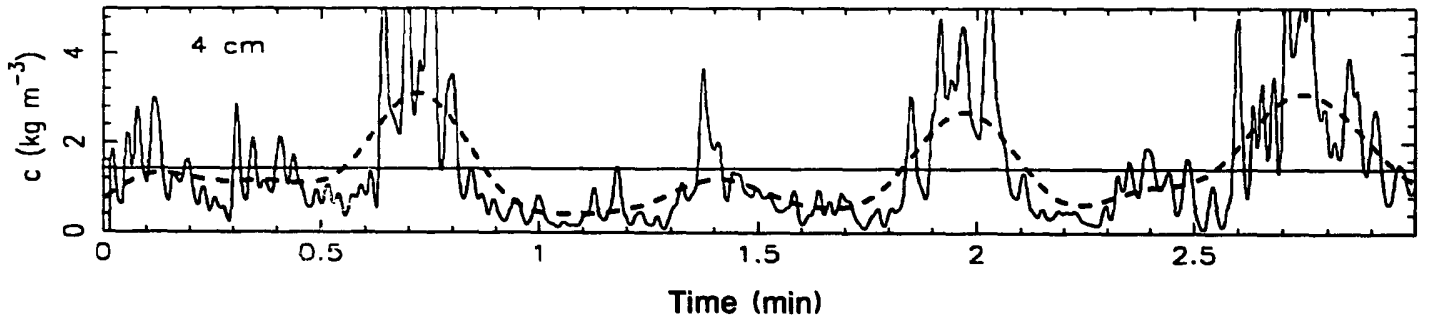

Fig. 5. (a) Cross-shore velocity $(z \approx 0.10 \mathrm{~m}$ : solid line) and suspended sediment concentration ( $\approx \approx 0.04 \mathrm{~m}$; dashed line) spectra from the $85 \mathrm{~m}$ station under shoaling waves $\left(H_{\mathrm{s}} / \boldsymbol{h}=0.15\right)$. (b) Co-spectrum of cross-shore velocity and sediment concentration; (c) time series of cross-shore velocity (solid line) and band-pass filtered velocity (dashed line); (d) the cross-product of velocity and suspended sediment concentration (solid line) and the band-pass filtered series (dashed line).

part, the offshore directed net oscillatory transport associated with the low frequencies (Figs. $5 b$ and 6). These observations are consistent with those made previously for shoaling wave groups on a non-barred shoreface (OG92) and with observations under non-breaking waves by other workers (e.g. Huntley and Hanes, 1987; Doering and Bowen, 1989). The important conclusion is that the response of cohesionless sediment to shoaling wave motion in both barred and non-barred environments and the resulting suspended sediment flux, depends critically not only upon the instantaneous velocity (shear) associated with the large amplitude, short period wind waves, but also upon the low frequency modulation associated with the propagation of groups of large waves.

Spilling breakers $\left(\boldsymbol{H}_{\mathrm{s}} / \boldsymbol{h}>0.2\right)$

As the June 16 storm progressed, waves steepened and the larger waves began to spill across the upper lakeward slope and bar crest of the second bar as the significant height-to-water depth ratio exceeded 0.2 . At this time $(1240 \mathrm{~h})$ the kinetic energy at the incident wave frequency had approximately doubled from its magnitude at $0738 \mathrm{~h}$ (cf. Fig. 6a and c). Over the same time period the spectral variance associated with the peak fre- 
quency of the infragravity band had increased by more than $400 \%$ as had the sediment transport associated with this frequency band (cf. Fig. 6a and c). By $1240 \mathrm{~h}$ the magnitude of sediment transport at low frequencies was at least equal to that attributable to the wind-wave band recorded much earlier (cf. Fig. 6a and c).

Under breaking waves the wind-wave component of suspended sediment transport exhibited considerable variability, with sediment fluxes directed both onshore and offshore. At $1240 \mathrm{~h}$, for example, the cospectrum exhibited a complex multimodal distribution indicating both onshore and offshore transport (Fig. 6c); integration of the cospectrum revealed that the net oscillatory suspended sediment transport was, however, approximately zero. With no significant shift in either the magnitude or the distribution of kinetic energy, the cospectrum at $1459 \mathrm{~h}$ revealed a simpler bimodal pattern at wind-wave frequencies, but now with an offshore net oscillatory transport (cf. Fig. 6c and d). By $2104 \mathrm{~h}$, as the wave-height-towater depth ratio decreased, a simple unimodal cospectral structure with an onshore net oscillatory transport was re-established (Fig. 6f).

The transitions from a net onshore oscillatory transport, to a balanced onshore and offshore transport, to a predominantly offshore transport and finally to a net onshore oscillatory transport over the full range of wind-wave frequencies coincided with a shift from wave shoaling to breaking and back to shoaling. These transitions may be explained by changes in the time-velocity relationships under increasingly skewed and asymmetric waves and by the phase lags which exist between velocity and concentration (Osborne and Greenwood, 1992a). Under this hypothesis the lowest frequencies in the wind-wave band would always tend to induce an onshore transport of sediment; during the onshore phase of the motion, the larger speeds would induce larger concentrations, but the length of the onshore half-wave cycle would still be long enough to allow material to rise above the bed $(z \approx 0.04 \mathrm{~m})$ and be advected shoreward during the same half-wave cycle. At higher frequencies, the onshore phase of wave motion would still induce larger velocities and concentrations than the offshore phase; nevertheless, the time lag inher- ent in the ejection of sediment from the bed after it has been set in motion, coupled to the shorter length of time of the onshore phase of motion (compared to the offshore phase), would increase the probability of much larger flux couplings between the offshore phase of fluid motion and the larger concentrations induced by the onshore velocities. These transitions in the net oscillatory transport at wind wave frequencies also coincided with changes in the local bottom roughness (bedforms).

\section{Bedform constraints on suspended sediment transport}

Under small shoaling waves (e.g. 1035 h) relatively steep (steepness $\approx 0.12$ ), three-dimensional vortex ripples were most commonly observed (Ollerhead and Greenwood, 1990). These bedforms were asymmetric, with steeper landward slopes and separation vortices could be identified by the discrete "clouds" of suspended sediment shed from ripple crests (observed by video imagery and by divers). Particularly large vortices and/or large sediment concentrations were produced at rates of 1 to 3 times per minute during passage of the largest waves in a group (Ollerhead, 1989).

The time-averaged concentrations of suspended sediment associated with half-wave cycles as waves shoaled over a rippled bed have been examined previously (Greenwood et al., 1990). This analysis revealed consistently larger average concentrations associated with the onshore phases of motion, especially at the lowest measurement elevations where phase lags between the current forcing and sediment concentration were small. Table 2 documents differences between the average concentrations of sediment suspended by the onshore and offshore phases of both shoaling and breaking waves for two elevations above the rippled bed. A statistically significant difference occurs under shoaling waves, but only at the lowest elevation $(0606 \mathrm{~h}, z \approx 0.04 \mathrm{~m})$; no such difference can be detected at either elevation once waves begin to break $(1240 \mathrm{~h})$. Such observations would be consistent with the expected larger kinetic energies (and larger sediment concentrations) associated with the separation vortices induced by the larger onshore 
(a)
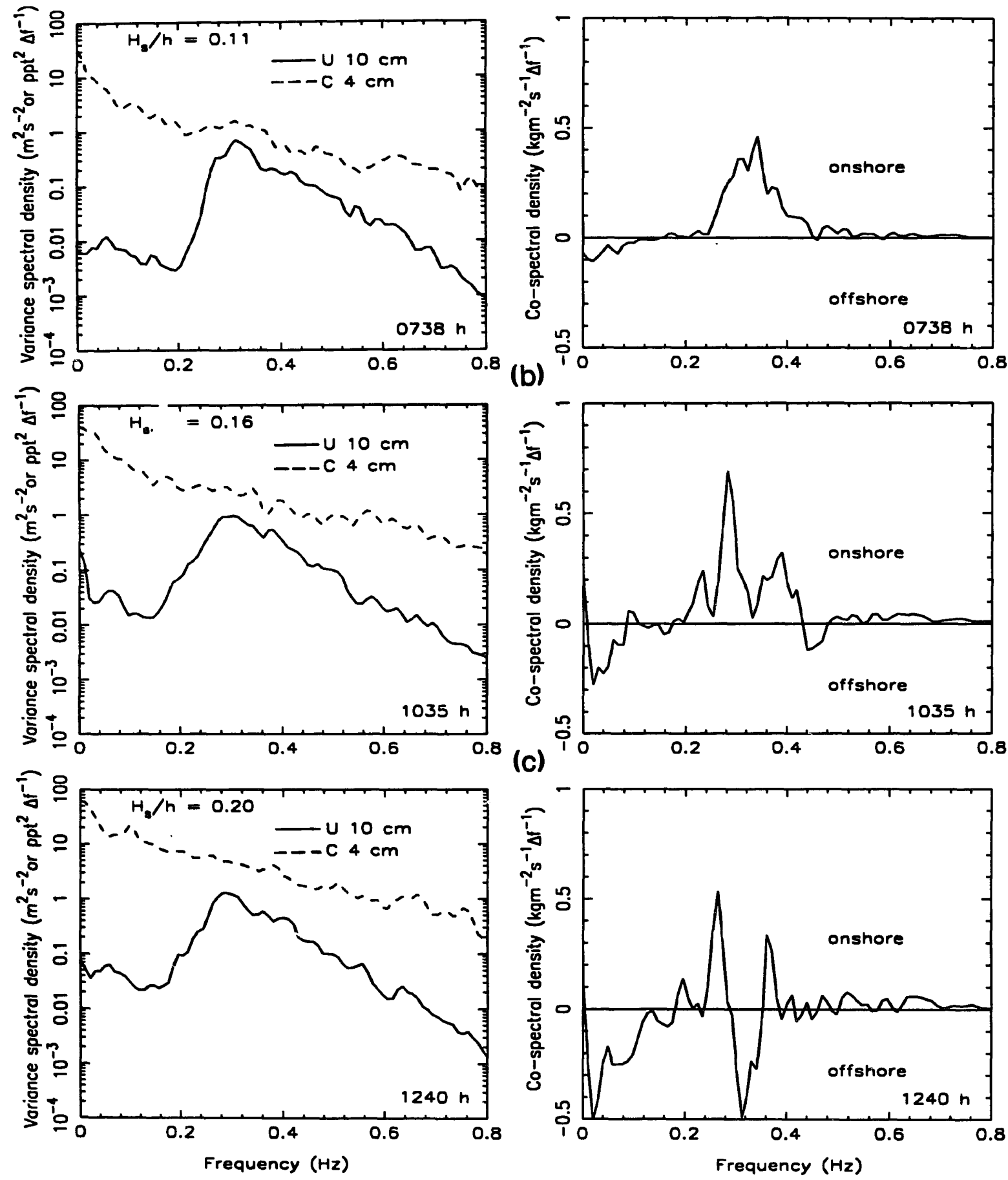

oscillatory velocities. This coupling of large sediment concentrations $(z \approx 0.04 \mathrm{~m})$ and large onshore velocities confirms the mechanism noted earlier for the dominant onshore net oscillatory transport

associated with wind-waves shoaling over a rippled bed ( $0738 \mathrm{~h}$ and $1035 \mathrm{~h}$; Fig. 6).

Under the increasingly skewed, asymmetric waves associated with the onset of breaking, the 

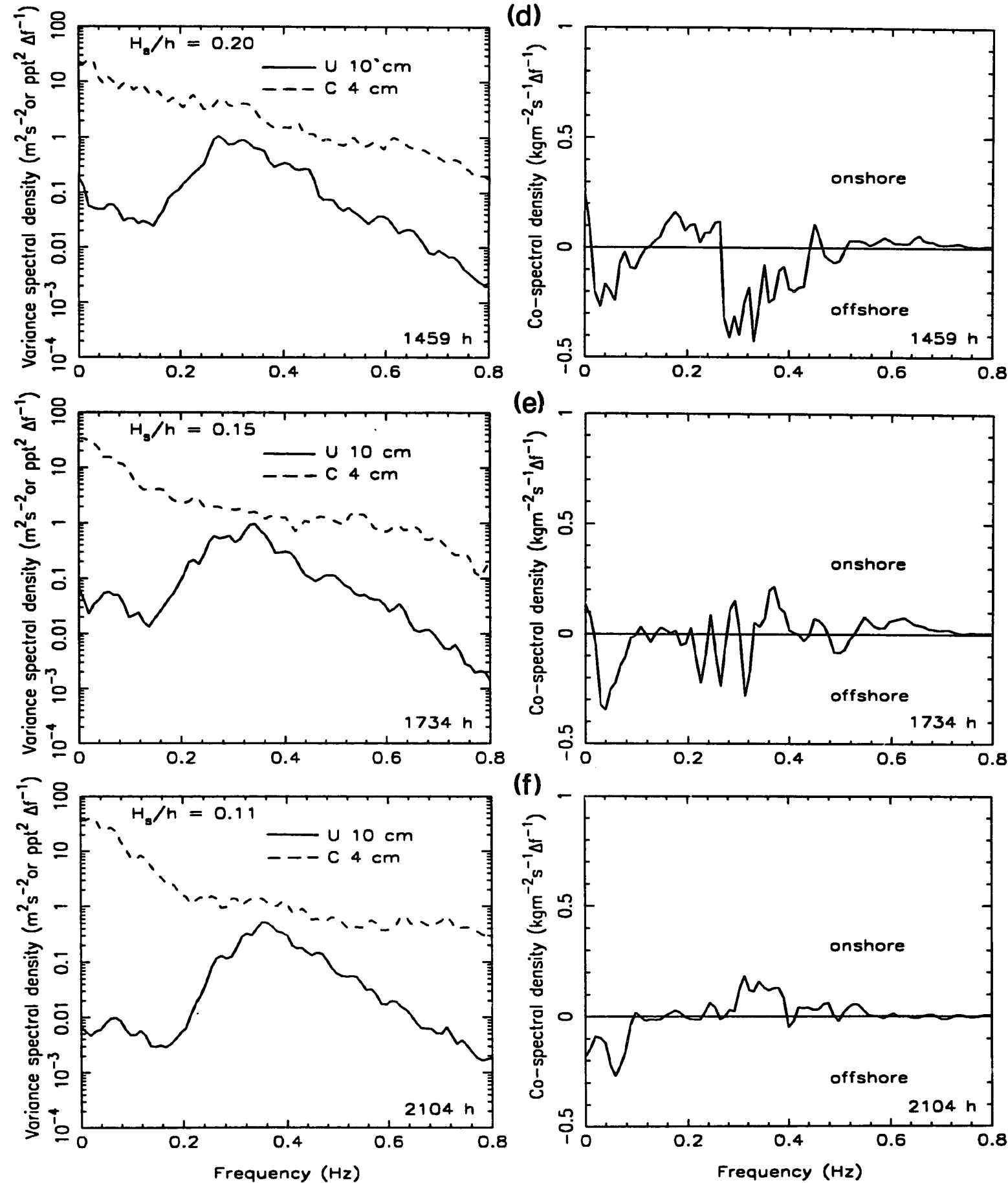

Fig. 6. Temporal variability of the cross-shore velocity $(z \approx 0.10 \mathrm{~m}$; solid line) and sediment concentration $(z \approx 0.04 \mathrm{~m}$; dashed line) spectra and the associated co-spectra $(z \approx 0.04 \mathrm{~m}$, solid line; $z \approx 0.10 \mathrm{~m}$, dot-dash line) from the $85 \mathrm{~m}$ station under a range of wave conditions: (a) $0738 \mathrm{~h}, H_{\mathrm{s}} / h=0.11$; (b) $1035 \mathrm{~h}, H_{\mathrm{s}} / h=0.16$; (c) $1240 \mathrm{~h}, H_{\mathrm{s}} / h=0.20$; (d) $1459 \mathrm{~h}, H_{\mathrm{s}} / h=0.20$; (e) $1734 \mathrm{~h}, H_{\mathrm{s}} / h=0.15$; (f) $2104 \mathrm{~h}, H_{\mathrm{s}} / \mathrm{h}=0.11$. 
TABLE 2

Difference of means test on suspended sediment concentrations during onshore and offshore phases of flow

\begin{tabular}{|c|c|c|c|c|c|c|c|c|}
\hline $\begin{array}{l}\text { Time } \\
\text { (h) }\end{array}$ & $\begin{array}{l}z \\
(\mathrm{~m})\end{array}$ & $-95 \%$ & $\begin{array}{l}C_{\text {on }} \\
(n) \\
\left(\mathrm{g}^{-1}\right)\end{array}$ & $+95 \%$ & $-95 \%$ & $\begin{array}{l}C_{\text {off }} \\
(n) \\
\left(\mathrm{g}^{-1}\right)\end{array}$ & $+95 \%$ & $\mathbf{S}$ \\
\hline 0606 & 0.10 & 0.32 & $\begin{array}{l}0.33 \\
(1512)\end{array}$ & 0.34 & 0.33 & $\begin{array}{l}0.34 \\
(2584)\end{array}$ & 0.35 & $\mathbf{N}$ \\
\hline 0606 & 0.04 & 1.04 & $\begin{array}{l}1.10 \\
(1512)\end{array}$ & 1.15 & 0.94 & $\begin{array}{l}0.98 \\
(2584)\end{array}$ & 1.02 & $*$ \\
\hline 1240 & 0.10 & 0.30 & $\begin{array}{l}0.31 \\
(1560)\end{array}$ & 0.33 & 0.28 & $\begin{array}{l}0.29 \\
(2536)\end{array}$ & 0.30 & $\mathbf{N}$ \\
\hline 1240 & 0.04 & 1.22 & $\begin{array}{l}1.30 \\
(1560)\end{array}$ & 1.38 & 1.13 & $\begin{array}{l}1.18 \\
(2536)\end{array}$ & $i .24$ & $\mathbf{N}$ \\
\hline
\end{tabular}

$z=$ elevation above bed; $C_{\text {on }}=$ mean sediment concentration during onshore flow; $C_{\text {off }}=$ mean sediment concentration during offshore flow; $+1-95 \%=$ upper/lower confidence limits on mean; $(n)=$ number of samples in mean; $\mathrm{S}=$ statistical significance; ${ }^{*}=$ significant at the $5 \%$ level; and $\mathrm{N}=$ not significant at the $5 \%$ level.

steep, three-dimensional, asymmetric, vortex ripples changed to less-steep (steepness $\approx 0.01$ ), twodimensional post-vortex ripples (Ollerhead and Greenwood, 1990). As a result, coherent vortex shedding from ripple crests was reduced. Timeaveraged sediment concentrations increased by $18-20 \%$ close to the bed $(z \approx 0.04 \mathrm{~m})$ as expected, but decreased slightly at higher elevations $(z \approx 0.10$ $\mathrm{m})$. This decrease most probably resulted from a reduction in mixing length, owing to the decreased amplitude of bottom roughness elements (see Nielsen, 1984); however, erosion of the bed and the resulting shift in relative elevation of the concentration sensors cannot be excluded as a cause. Differences in the time-averaged sediment concentrations between each half-wave cycle were now no longer statistically significant (Tabie 2); with this increased homogeneity of sediment concentration over the wave cycle, cross correlations between concentration and velocity would result in large onshore and offshore flux couplings. Consequently, the observed bidirectionality of transport over the incident wave band (Fig. 6, $1240 \mathrm{~h}$ ) is not surprising.

As breaking intensified, oscillation ripple steepness decreased further and sediment concentrations became relatively uniform (vertically) over the wave cycle. This increased uniformity coincided with a greater frequency of occurrence of offshore flows (associated with increased skewness and asymmetry of the breaking wave form) which would increase the potential flux coupling between offshore flows and large sediment concentrations. The dominant offshore net oscillatory transport by breaking wind-waves at $1459 \mathrm{~h}$ (Fig. 6d) can be accounted for in this way. With the reappearance of three-dimensional, vortex ripples as wave height and cross-shore velocities decreased, a net onshore sediment transport at wind-wave frequencies is observed once more $(1734 \mathrm{~h}$ and 2104 h, Fig. 6).

A simple sequence of suspended sediment flux appears to be closely linked to both the near-bed fluid dynamics and the bedforms as they change through time at a single location. Such a sequence might also be expected to occur spatially at a single point in time, since wave height-to-water depth ratios are a function of nearshore bathymetry.

\section{Spatial dependency of wave-induced suspended sediment transport}

Spatial variation in the cross-shore velocity field reflects both the character of the incident waves and the nearshore bathymetry. Thus the concentrations of suspended sediment and the oscillatory suspended sediment transport rates should exhibit at least as strong a spatial signature across a barred shoreface as that documented previously for a non-barred system (OG92). These signatures 
should be strongest when wave transformations are most pronounced.

Time series of the cross-shore velocity and sediment concentration from the lakeward slope, crest and lower landward slope/trough of the second bar recorded close to the storm peak $(1600 \mathrm{~h})$ illustrate the extremes for such transformations. Across the lakeward slope a well-defined "groupiness" is evident in the velocity field (Fig. 7a), as waves shoaled but were not yet breaking. Equally well-defined are sediment re-suspension events marked by large concentrations lasting for several wave periods and in-phase with the groupmodulated velocities.

At the bar crest the larger waves were spilling. Although group modulation of the velocity field was reduced as a result of the breaking process, discrete re-suspension events can still be recognized (Fig. 7b) and are coherent with those observed at the $85 \mathrm{~m}$ station. The time lag recorded is directly proportional to the group propagation speed (Table 3). This confirms the importance of wave groups in re-suspending and transporting sediment even after significant dissipation of wave energy through breaking.

In the trough, most waves were breaking or reforming and group-modulation of the cross-shore velocities is even less well-defined (Fig. 7c). Nevertheless, a distinct low-frequency modulation of the

\section{TABLE 3}

Time lags of maximum correlation between stations for crossshore velocity and sediment concentration

\begin{tabular}{llll}
\hline Stations & $85-63 \mathrm{~m}$ & $85-55 \mathrm{~m}$ & $63-55 \mathrm{~m}$ \\
\hline$d x(\mathrm{~m})$ & 22 & 30 & 8 \\
$d h(\mathrm{~m})$ & 1.0 & 0.6 & 0.4 \\
$C\left(\mathrm{~m} \mathrm{~s}^{-1}\right)$ & $3.6(1.8)$ & $3.8(1.9)$ & $3.1(1.6)$ \\
$t(\mathrm{~s})$ & $6.1(12.2)$ & $7.8(15.5)$ & $2.6(5.2)$ \\
$R_{\max -u}(\mathrm{~s})$ & 7.0 & 9.0 & 2.0 \\
$R_{\max -c}(\mathrm{~s})$ & 12.0 & 7.3 & 9.0 \\
\hline
\end{tabular}

$d x=$ separation distance between stations; $d h=$ change in water depth between stations; $C=$ average phase (group) velocity between stations $=1 / N \sum\left(g h_{\mathrm{i}}\right)^{0.5}$, where $h_{\mathrm{i}}=$ local depth $(\mathrm{m})$. $N=$ number of depih increments between stations; $t=$ wave (group) travel times between stations; $R_{\max -u}=$ time lag of maximum correlation for velocity; and $R_{\max -c}=$ time lag of maximum correlation for concentration. velocity field is superimposec on the high frequency oscillations of the breakers. Sediment resuspension events in the trough are closely correlated with the local low-frequency oscillation, but are not coherent with re-suspension events on either the bar crest or the lakeward slope. The time lags of maximum correlation for sediment concentration between the $55 \mathrm{~m}$ station and those at 85 and $65 \mathrm{~m}$ are not compatible with a groupmodulated forcing (Table 3 ) even though the time lag of maximum correlation between cross-shore velocities is consistent with the propagation of the same wave field. It would appear, therefore, that the low frequency modulation of the cross-shore velocity field in the trough is not of the same origin as that on the lakeward slope and bar crest.

As waves shoaled to breaking between the 85 and $63 \mathrm{~m}$ stations, the cross-shore velocity spectra revealed significant increases in variance at frequencies $\leqslant 0.2 \mathrm{~Hz}$ (Fig. $8 \mathrm{a}$ and $\mathrm{b}$ ). A further increase in low-frequency energy $(\leqslant 0.05 \mathrm{~Hz})$ is observed between the 63 and $55 \mathrm{~m}$ stations (Fig. 8b and c) as spilling breakers propagate from the bar crest across the trough. The low-frequency oscillation associated with the shoaling wave field reflects clearly the presence of a group-bound forced long wave (see also Greenwood and Osborne, 1992; Osborne and Greenwood, 1992a). In contrast, lowfrequency oscillations in the trough most probably represent energy transferred from the forced long wave to long waves constrained by the presence of the bar crest and the time-varying position of the breaker line (e.g. Symonds and Bowen, 1984). Regardless of the actual wave mode, the oscillatory transport rates at low-frequencies landward of wave breaking should be coherent with this new secondary wave; this would explain the observed lack of coherence between the low-frequency oscillatory transport in the trough and that on the lakeward slope and bar crest.

An equally significant increase in high-frequency energy between the bar crest and the trough was observed at the storm peak (Fig. $8 b$ and c). The spectral peak centred around $0.6 \mathrm{~Hz}$ represents the first harmonic of the primary wave; harmonics such as this are typical of the spectra of extremely asymmetrical wave forms associated with the highly non-linear waves and surf bores triggered 
(a)

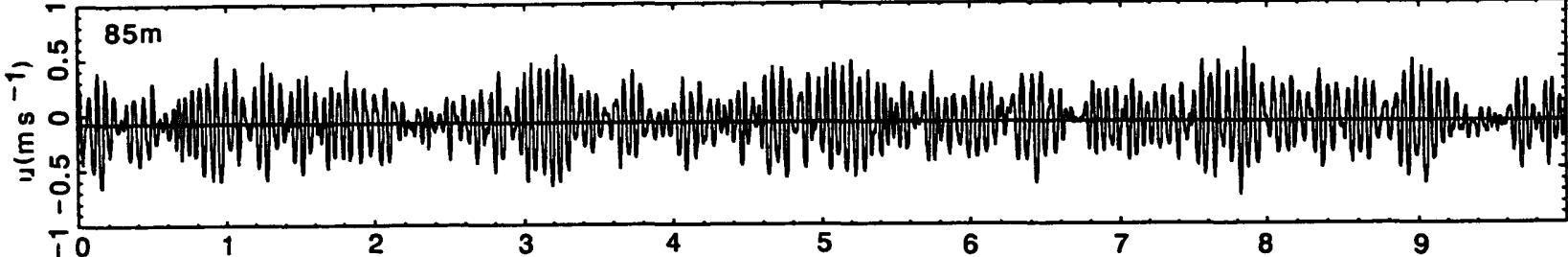

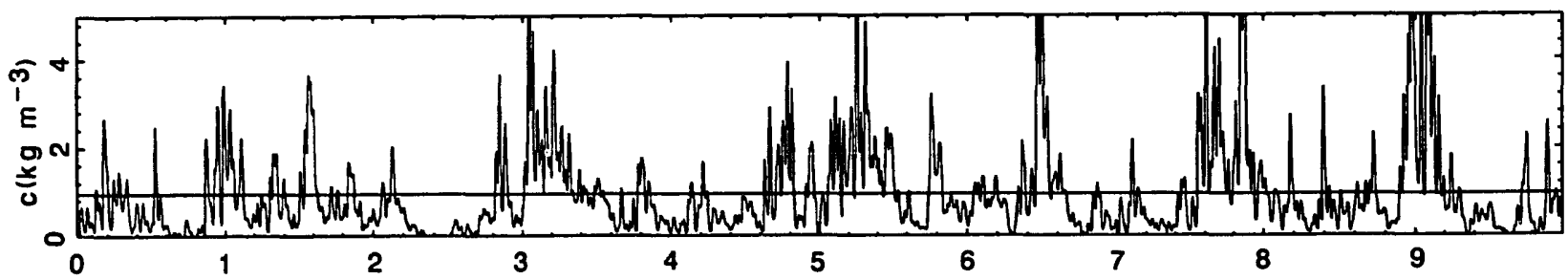

(b)
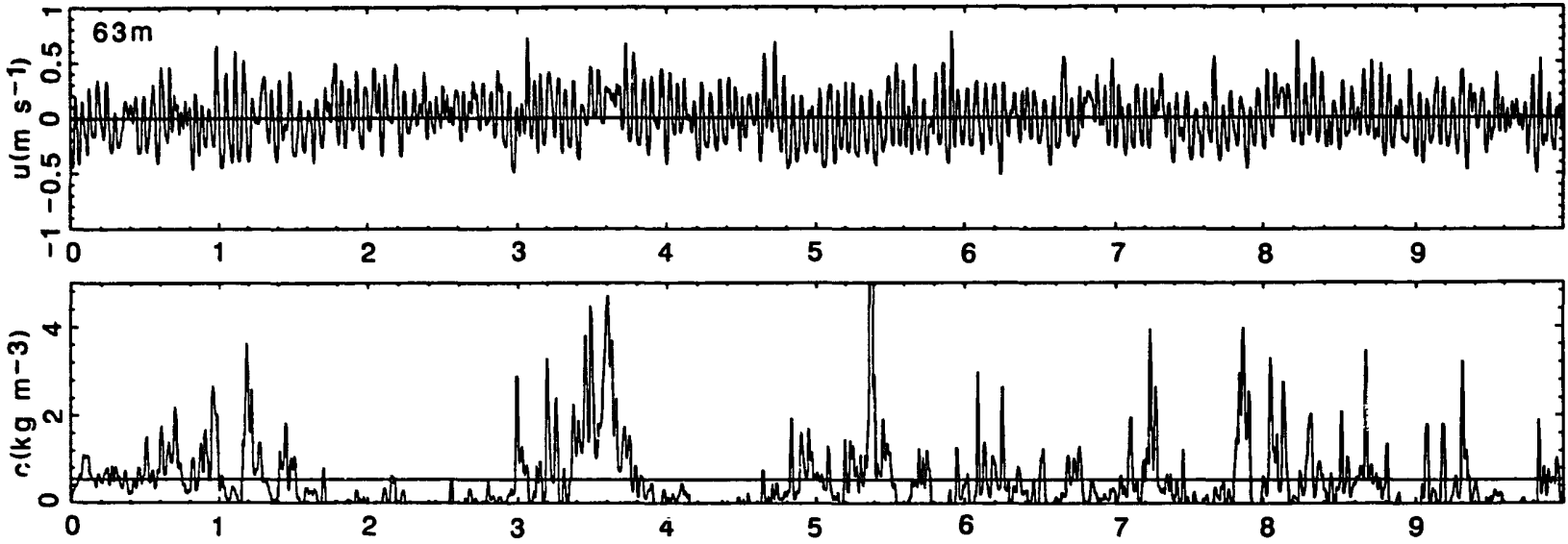

(c)
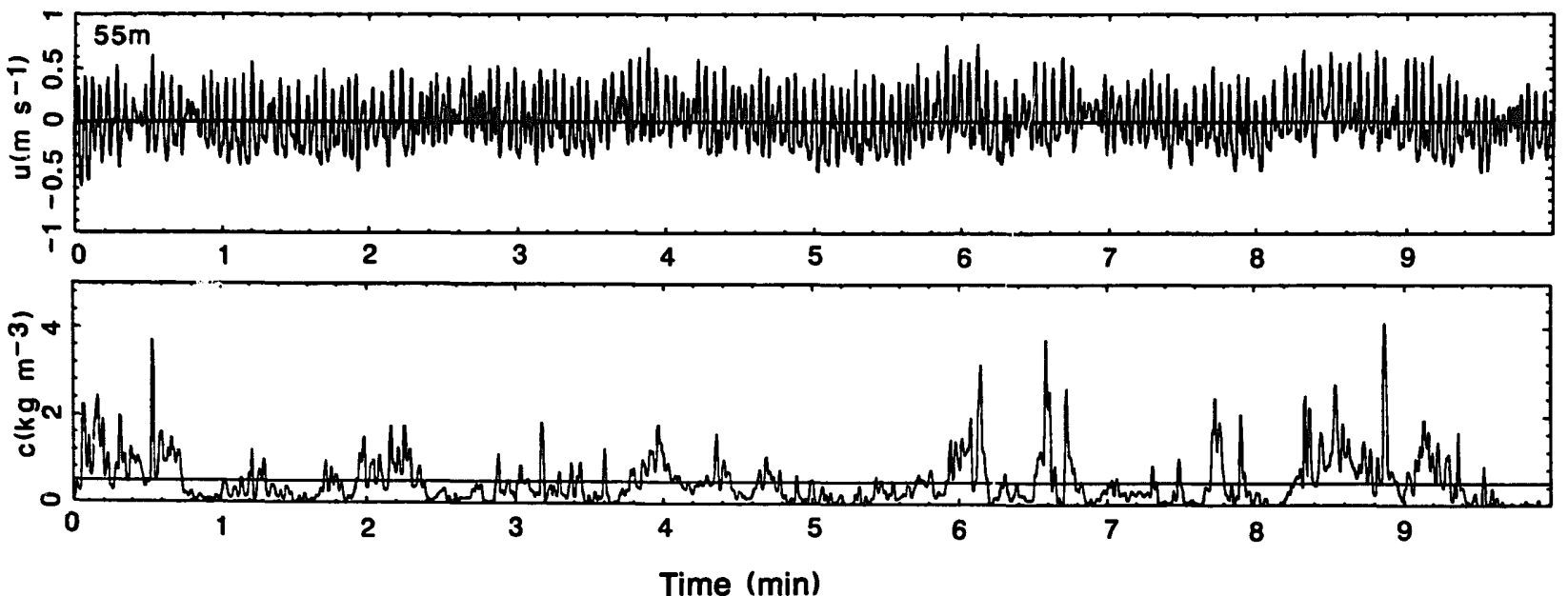

Fig. 7. T $\mathrm{me}$ series of the cross-shore velocity $(u ; z \approx 0.10 \mathrm{~m})$ and suspended sediment concentration $(c ; z \approx 0.04 \mathrm{~m}):(\mathrm{a}) 85 \mathrm{~m}$ station $\left(H_{\mathrm{s}} / h=0.15\right)$; (b) $63 \mathrm{~m}$ station $\left(H_{\mathrm{s}} / h=0.41\right)$; (c) $55 \mathrm{~m}$ station $\left(H_{\mathrm{s}} / \mathrm{h}=0.28\right)$. 


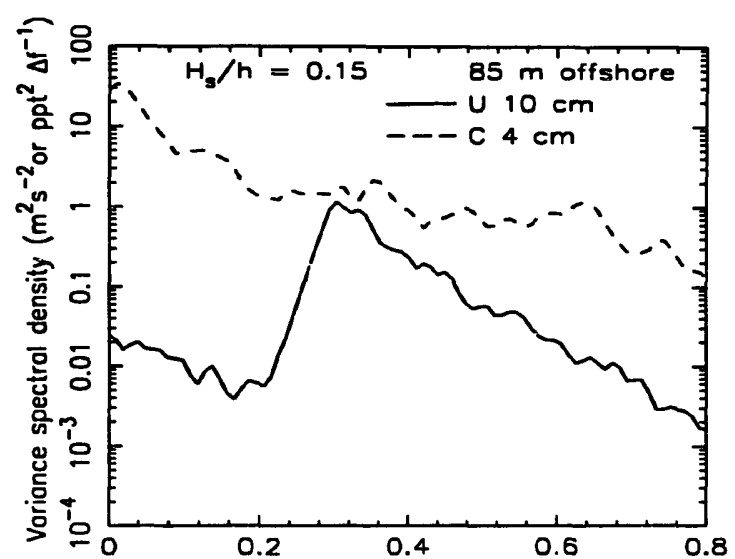

(a)

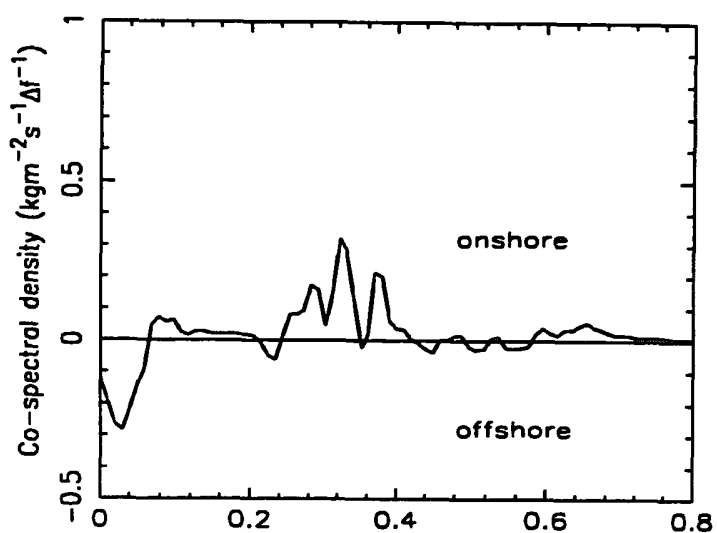

(b)
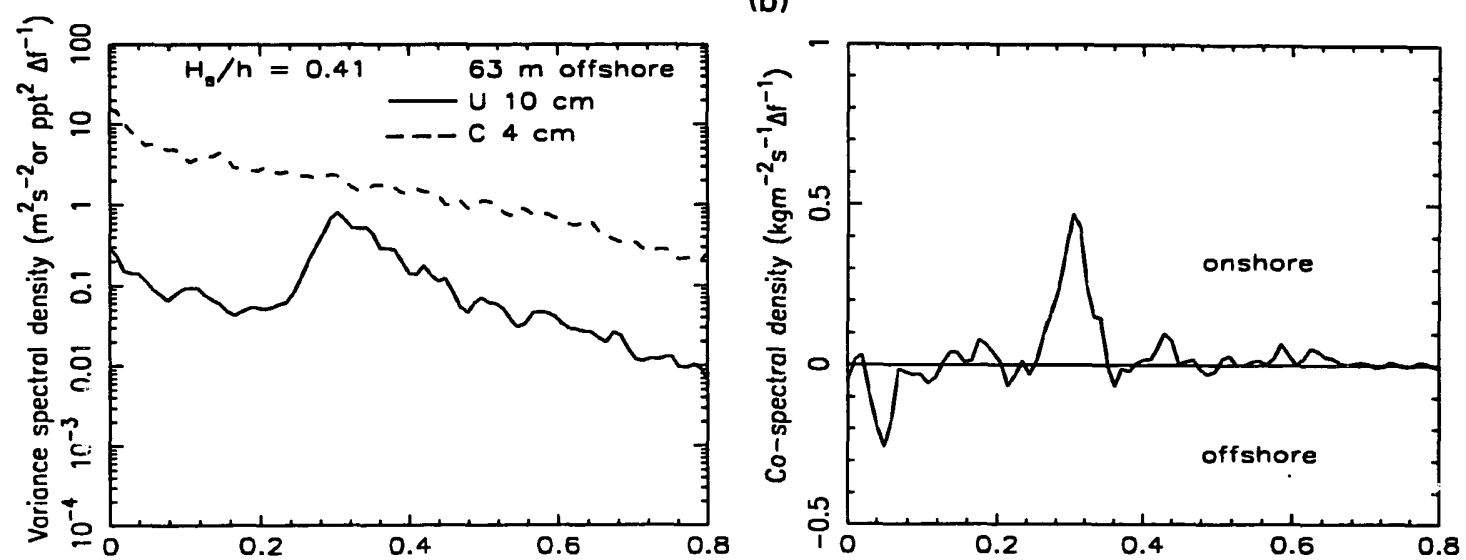

(c)
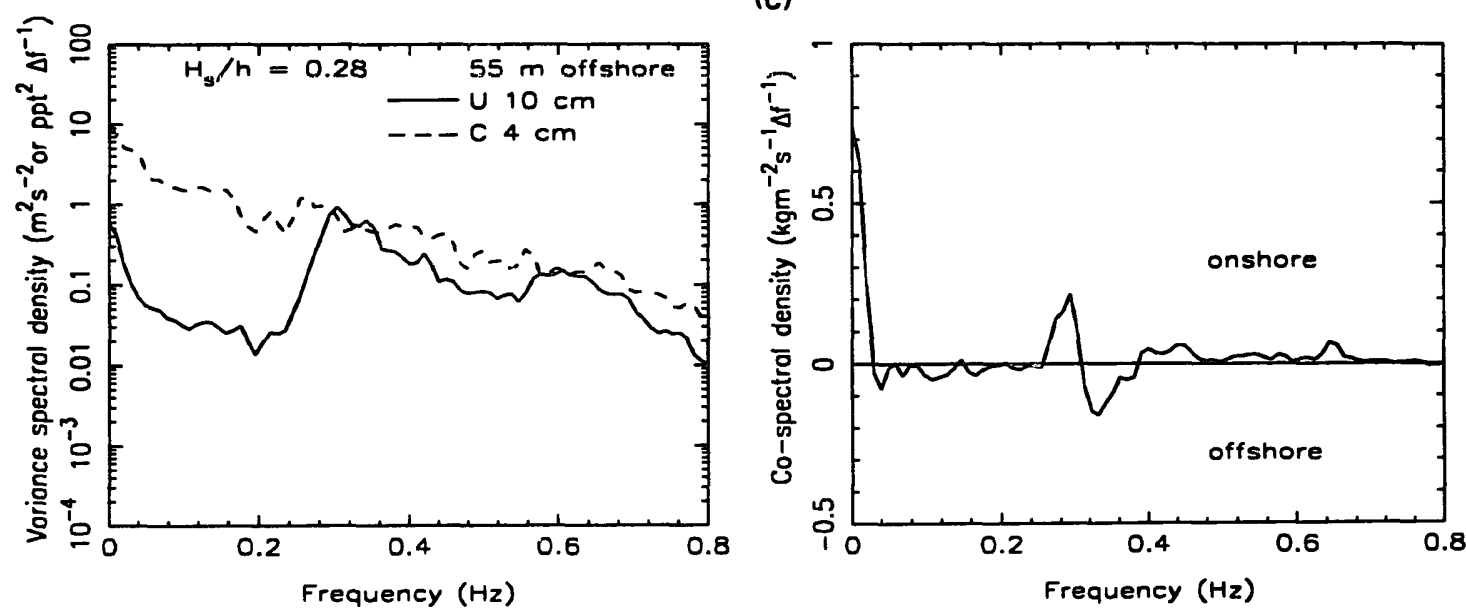

Fig. 8. Spatial variability of cross-shore velocity ( $z \approx 0.10 \mathrm{~m}$; solid line) and sediment concentration $(z \approx 0.04 \mathrm{~m}$; dashed line) spectra and the associated co-spectra $\left(z \approx 0.04 \mathrm{~m}\right.$, solid line) under a range of wave conditions: (a) $85 \mathrm{~m}$ station, $H_{\mathrm{s}} / h=0.15$; (b) $63 \mathrm{~m}$ station; $H_{\mathrm{s}} / \boldsymbol{h}=0.41$; (c) $55 \mathrm{~m}$ station, $H_{\mathrm{s}} / \boldsymbol{h}=0.28$.

by the breaking on the bar crest (Thornton et al., 1977; Greenwood and Osborne, 1991a). The combined effects of redistributing energy towards both lower and higher frequencies during wave shoaling and breaking results in a greater potential for significant transport of suspended sediment at these frequencies. Spatial variation in the cospectra reinforce many of the earlier conclusions concerning sediment transport drawñ from both the time-series and variance spectra. On the lake- 
ward slope of the bar ( $85 \mathrm{~m}$ station, Fig. 8a), where waves were shoaling but not breaking, suspended sediment transport at wind-wave frequencies was directed onshore, while that attributable to the low frequencies was directed offshore. The co-spectrum indicates that the total onshore and offshore oscillatory transport rates are nearly equal, with the balance being achieved across frequency space. On the bar crest $(63 \mathrm{~m}$ station, Fig. $8 b$ ), the onshore wind-wave transport rates increased dramatically from those on the lakeward slope ( $85 \mathrm{~m}$ station). This reflects both the increase in sediment re-suspension in shallower water and the increase in velocity skewness and asymmetry as a result of the shoaling transformations across the lakeward slope. The offshore directed oscillatory transport rates in the infragravity band decreased from the lakeward slope to the bar crest (cf. Fig. 8b and a). This is to be expected as the wave group structure is diminished during the breaking process and the forced long wave is released.

In the trough of the second bar (55 $\mathrm{m}$ station, Fig. $8 \mathrm{c}$ ), $8 \mathrm{~m}$ landward of the bar crest, the transport rates at wind-wave frequencies are greatly reduced, reflecting the dissipation of energy as a result of both wave breaking and a cascading of energy to lower frequencies. A reduction in energy density also results from the increase in water depth from crest to trough $(1.00 \mathrm{~m}$ to 1.38 $\mathrm{m})$. At this time the cospectrum was also distinctly bimodal over the wind-wave frequency range, with approximately equal transport rates directed onshore (peak wave frequency and highest frequencies) and offshore (intermediate frequencies). However, the most distinctive feature of the cospectrum from the trough is the very large onshore suspended sediment transport rates at frequencies $<0.05 \mathrm{~Hz}$; this was a characteristic feature of virtually all the spectra from this location for a major portion of the storm event on June 16 (1035 to $1734 \mathrm{~h}$ ).

The complex bimodal structure of the cospectrum at the incident wave frequencies, together with the unimodal structure at low frequencies, supports the observation that sediment concentration fluctuations are out of phase with velocity fluctuations at the wind-wave frequencies but in phase with fluctuations associated with relatively large low frequency waves in the inner surf zone.

(a)

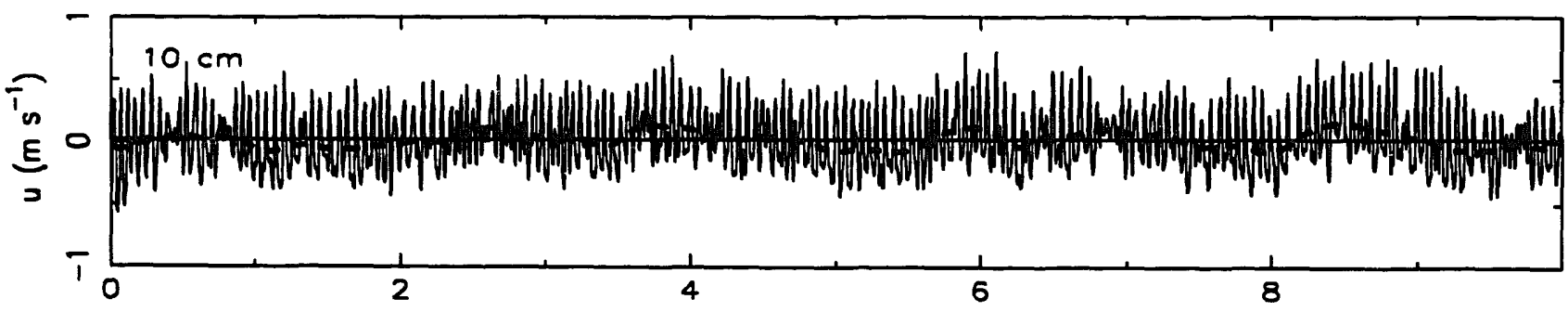

(b)

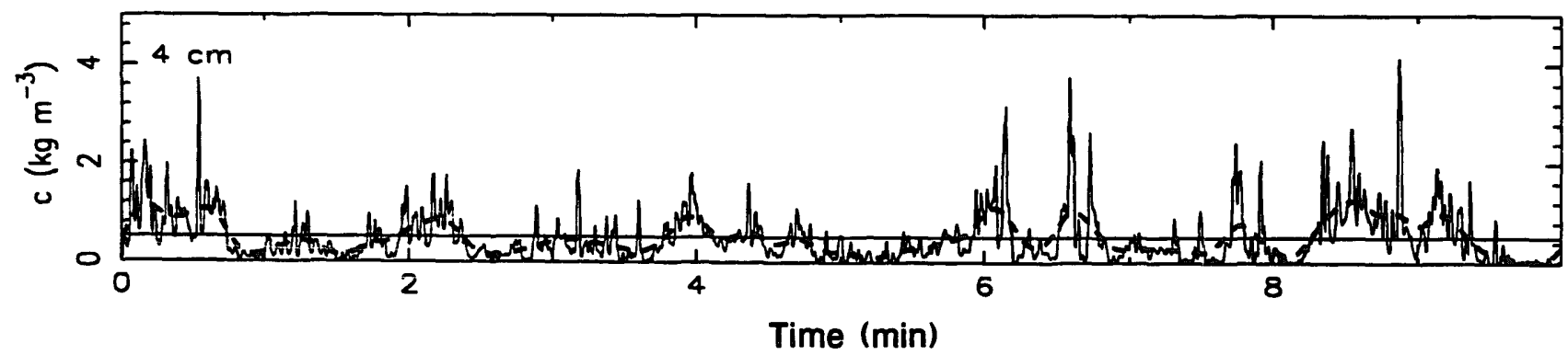

Fig. 9. Observed (solid line) and low pass filtered (dashed line) time series of cross-shore velocity (a) and suspended sediment concentration (b). 
To confirm this suggestion, the cross-shore velocities and sediment concentrations ( $55 \mathrm{~m}$ station) were low-pass filtered with a cutoff frequency of $0.1 \mathrm{~Hz}$; excellent coherence was obtained between onshore phases of the low frequency wave and major re-suspension events (Fig. 9a).

Relatively large offshore transport rates were associated with low frequency motions over the bar crest between $1240 \mathrm{~h}$ and $1734 \mathrm{~h}(63 \mathrm{~m}$ station, Fig. 8b). However, the co-spectra from $63 \mathrm{~m}$ demonstrated substantially larger onshore transport rates at the wind wave frequencies than those at $55 \mathrm{~m}$. This spatial pattern of sediment transport reflects the decreasing importance of incident waves and the relative increase in importance of low-frequency oscillations landward of the bar crest (e.g. Wright et al., 1986).

\section{Suspended sediment transport by time-averaged cross-shore currents}

The presence of several bars on a shoreface has been shown previously to be associated with spatially periodic perturbations in the local timeaveraged (mean) cross-shore currents during storms (Greenwood and Osborne, 1991). These mean currents were directed offshore, forming classic undertows in response to cross-shore gradients in wave setup superimposed on the wind setup as waves break across each individual bar (Greenwood and Osborne, 1990). Since the time-averaged (mean) concentrations of suspended sediment are a function of the depth-controlled oscillatory velocities, then spatially periodic perturbations in the mean suspended sediment transport rates should be expected.

Prior to the storm the mean cross-shore currents were small and directed onshore, but reversed as the storm waves began to build (0330 h, Fig. 4). Through the subsequent storm a consistent pattern of cross-shore mean currents emerged (Figs. 4 and 10). Such currents were always a minimum across the bar crest ( $63 \mathrm{~m}$ station) dropping to near zero $\left(0.01 \mathrm{~m} \mathrm{~s}^{-1}\right)$ at the storm peak $(1530 \mathrm{~h})$. Maximum mean currents were observed at the storm peak on both the lakeward slope $\left(0.11 \mathrm{~m} \mathrm{~s}^{-1}\right)$ and in the trough $\left(0.10 \mathrm{~m} \mathrm{~s}^{-1}\right)$ of the second bar. In contrast, the mean suspended sediment concen- trations were at a minimum in the trough and reached a maximum over the bar crest at the storm peak (1530 h, Fig. 10). The significantly lower mean cross-shore currents over the bar crest accounted for the low mean transport, even though mean sediment concentrations peaked at this location (Fig. 10); at $1500 \mathrm{~h}$, for example, the mean transport on the lakeward slope (85 $\mathrm{m}$ station) was larger by at least a factor of four.

Wave breaking intensified over the bar crest and upper lakeward slope of the second bar during the storm peak and mean water levels recorded at the 85,63 and $55 \mathrm{~m}$ stations indicated increases of 0.07 to $0.10 \mathrm{~m}$ (relative to pre- and post-storim levels) and a maximum increase of $0.20 \mathrm{~m}$ even further shoreward (Hazen et al., 1991). The wave setup gradients were small compared to the overall wind-induced lake setup, which accounts for the small mean cross-shore currents. Larger magnitude currents have been observed by previous workers and shown to be spatially extensive across a variety of barred profiles in Southern Georgian Bay (e.g. Greenwood and Sherman, 1984; Davidson-Arnott and McDonald, 1989; Greenwood and Osborne, 1990, 1991; Osborne and Greenwood, 1991). The mean cross-shore currents of June 16 were weak undertows, driven by spatially variable set-up gradients; the offshore mean flow at $55 \mathrm{~m}$ being driven by set-up across the innermost bar and that at $85 \mathrm{~m}$ by set-up across the second bar (for a more detailed analysis see Hazen et al., 1991).

\section{Net suspended sediment transport rates}

As incident wave energy increased during the June 16 storm, so did the magnitudes of both the oscillatory and mean suspended sediment transport rates. Mass balance in the shoreface results, at least in part, from the relative magnitudes and directions of suspended sediment transport attributable to these components as a function of time, cross-shore position and distance above the bed.

\section{Vertical structure of suspended sediment transport}

Figure 11 illustrates the local vertical variations in $\langle u c\rangle_{\text {mean }}$ and $\langle u c\rangle_{\text {osc}}$, the sum of which equals the time-averaged, net suspended sediment 

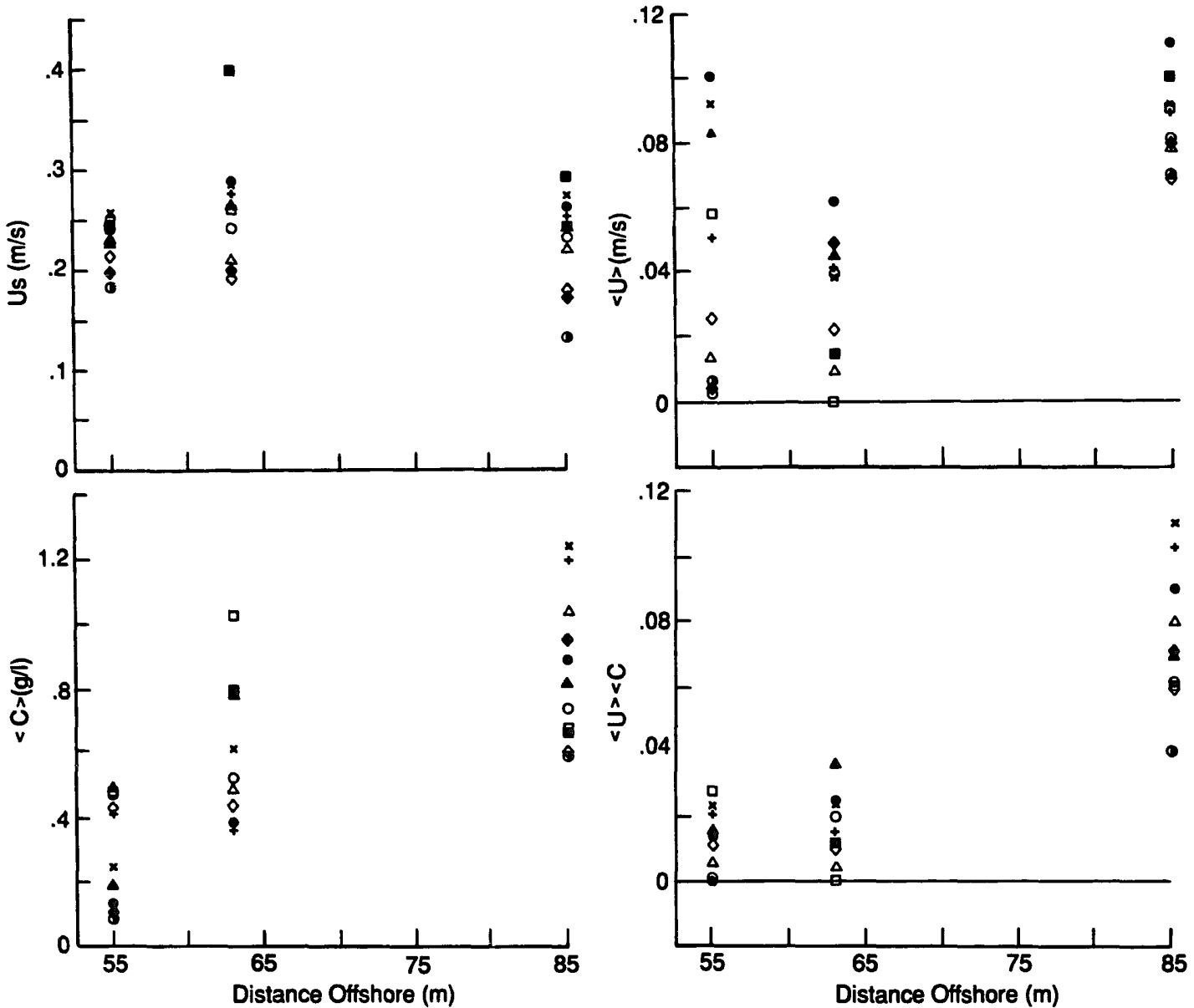

$\circ 0323 h \circ 0427 h \quad \Delta 0606 h \circ 0738 h+1035 h \times 1240 h \cdot 1459 h \quad-1529 h \quad 1734 h \bullet 2104 h \circ 2317 h$

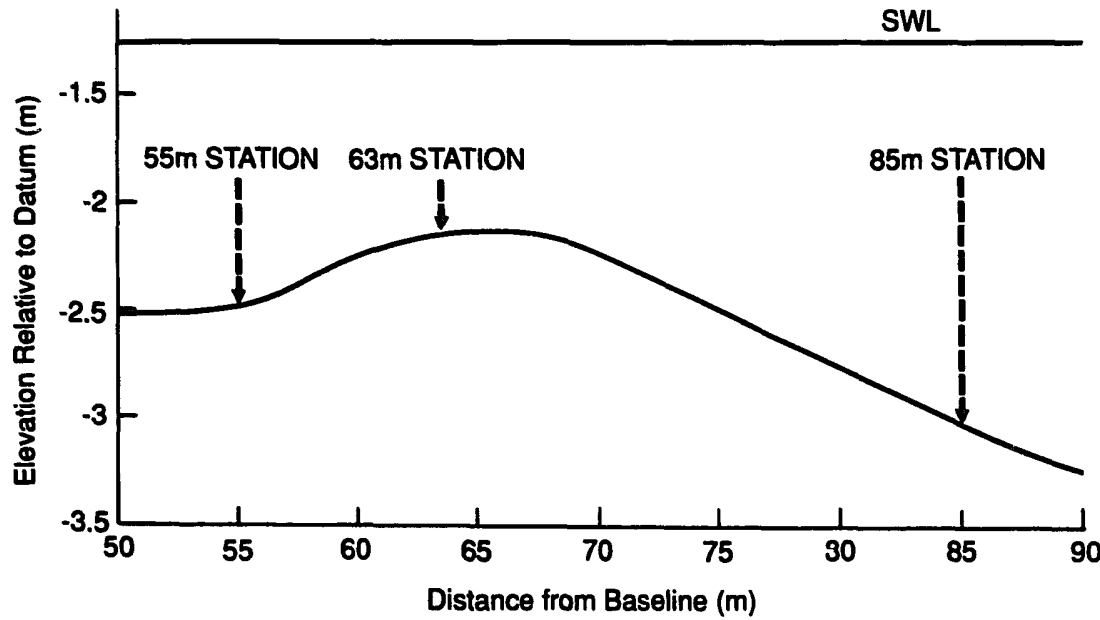

Fig. 10. Depth-dependent patterns in the cross-shore oscillatory velocity $\left(u_{\mathrm{s}} ; z \approx 0.10 \mathrm{~m}\right)$, cross-shore mean current speed $\left(\bar{u}_{;}: z 0.10 \mathrm{~m}\right)$, time-averaged suspended sediment concentration $(\bar{c} ; z \approx 0.08 \mathrm{~m})$, and mean suspended sediment transport rate $(\bar{u} \bar{c})$. 

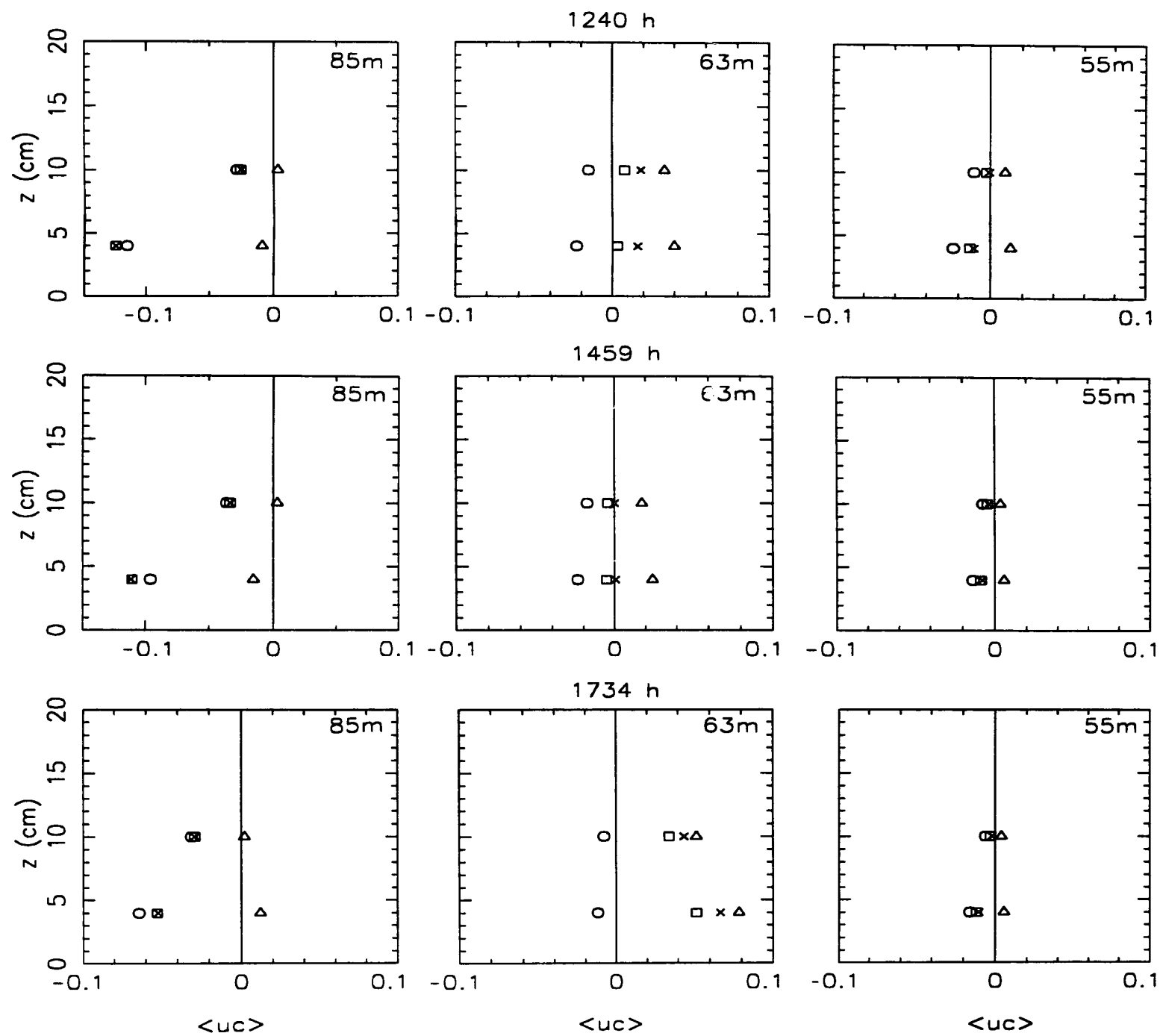

$$
\begin{aligned}
& \text { - } \quad \text { iuc }>_{\text {total }}=1 / n \sum u c \\
& 0\langle u c\rangle_{\text {mean }}=1 / n \sum u+1 / n \Sigma c
\end{aligned}
$$

$$
\begin{aligned}
& \Delta\langle u c\rangle_{o s c}=\Delta f / f_{c} \Sigma C_{u c}(f) \\
& x\langle u c\rangle_{\text {total }}=\langle u c\rangle_{\text {mean }}+\langle u c\rangle_{\text {osc }}
\end{aligned}
$$

Fig. 11. Time-averaged suspended sediment transport across the bar form $(z \approx 0.04$ and $0.08 \mathrm{~m})$ over the storm peak $(1240-$ $1734 \mathrm{~h}$ ): lakeward slope ( $85 \mathrm{~m}$ station); bar crest $(63 \mathrm{~m}$ station); landward trough $(55 \mathrm{~m}$ station). Note: positive values of $<u c>$ signify onshore transport.

transport rate, $\langle u c\rangle$. On the lakeward slope (85 m station, Fig. 11) the $\langle u c\rangle_{\text {mean }}$ was directed offshore at both the 0.04 and $0.08 \mathrm{~m}$ elevations and clearly dominated the net transport rate at this location throughout this period of time. During the buildup and peak of the storm $\langle u c\rangle_{\text {osc }}$ was also directed offshore at the lowermost elevation $(z \approx 0.04 \mathrm{~m})$ owing to the relatively large component of offshore transport associated with the group-bound, forced long wave. Together with the offshore mean transport rate the result was a large net offshore transport rate near the bed. At $z \approx 0.08$ $\mathrm{m}$, the $\langle u c\rangle_{\text {osc }}$ was directed landwards, but was small compared to the offshore directed $\langle u c\rangle_{\text {mean }}$ resulting in a net offshore transport of sediment in the lower water column.

On the bar cresi during the peak of the storm the net suspended sediment transport rate was near zero at both measirement elevations (Fig. 11, $63 \mathrm{~m}$ station, $1459 \mathrm{~h}$ ). This resulted from the nearly equal but opposing offshore directed $\langle u c\rangle_{\text {mean }}$ and onshore directed $\langle u c\rangle_{\text {osc }}$. The 
latter was forced by the positive (landward) skewness in the velocity field associated with the nonlinear form of the breaking waves. During the early part of the storm $(1240 \mathrm{~h})$ and particularly during the decay phase $(1734 \mathrm{~h})$, however, $\langle u c\rangle_{\text {total }}$ was was directed onshore across the bar crest. This resulted from strongly asymmetric oscillatory currents inducing large onshore transport rates, which could not be offset by offshore transport associated with the relatively weak mean currents.

In the trough landward of the bar crest (Fig. 11, $55 \mathrm{~m}$ station), transport rates were much smaller overall than on either the bar crest or lakeward slope. The undertow induced $\langle u c\rangle_{\text {mean }}$ was slightly larger than $\langle u c\rangle_{\text {osc }}$, which in this case was dominated by the secondary low frequency waves in the inner part of the surf zone. The result was a small but persistent net offshore sediment flux throughout the lower water column.

During the peak of the storm $\langle u c\rangle_{\text {total }}$ was directed offshore across both the lakeward slope and the trough landward of the second bar. On the lakeward slope, the net offshore transport was driven by both the mean cross-shore currents (undertow) and the group-bound, forced long wave. In the trough, the net offshore transport was dominated by the mean cross-shore currents. In contrast, the bar crest was characterized by a near-zero net suspended sediment transport rate. Thus, although the bar crest was an area of considerable sediment re-susfension owing to the large magnitude oscillatory surrents and the enhanced turbulence associated with wave breaking, net suspended sediment transport rates were small. The latter would appear to have been achieved by a balance between the transport of sediment offshore by the time-averaged mean currents and the group-forced long wave, and the landward transport of sediment due to the skewed oscillatory velocity field under near-breaking and breaking waves. Oscillatory sediment transport driven by the incident wave frequencies clearly declined away from the bar crest down both the landward and lakeward slopes, and the contributions to the local sediment transport rates from both the low frequency oscillations and the mean currents became dominant.
It is useful to explore the implications of the measured suspended sediment flux rates in terms of the potential for erosion or accretion. With relatively large offshore transport rates on the lakeward slope of the bar and near-zero net transport raies on the bar crest, it might be expected that erosion of the lakeward slope would occur. Accretion would be expected on the upper landward slope or crest of the bar as a result of the net offshore transport rates in the trough and the near-zero net transport across the bar crest. These measured sediment flux rates indicate both a vertical growth and landward migration of the second bar during the storm.

\section{Sediment re-activation, volume flux and erosion- accretion patterns}

Sediment volume fluxes estimated from the depth-of-activity rod measurements for all the significant wave events monitored during the 1988 field season are summarized in Table 4. The June 16 storm was obviously not the most significant event in terms of sediment re-activation, ranking fifth in terms of the total amount of sediment reactivated but it did rank first in terms of the net morphological change. Furthermore, it follows a pattern similar to all other storms in that large volumes of sediment were reactivated, while the net sediment volume fluxes through the shoreface sand prism were small. Of the estimated total control volume for the shoreface of $1188 \mathrm{~m}^{3}$, approximately $8.6 \%$ was re-activated by the June 16 storm $\left(I T V F=101.8 \mathrm{~m}^{3}\right)$. A small net gain of sediment $\left(I N V F=22.9 \mathrm{~m}^{3}\right)$, equivalent to $1.9 \%$ of the control volume was also recorded. If the change in sediment volume is taken relative to the volume re-activated, the percentage change is still not large. Over the second bar, with a partial-control volume of $300 \mathrm{~m}^{3}$, sediment re-activation equalled $10.6 \%$ of this control volume $\left(I T V F=31.66 \mathrm{~m}^{3}\right)$, with a net gain in this case of $3.2 \%$ of the partial control volume $\left(I N V F=9.53 \mathrm{~m}^{3}\right)$.

The patterns of depth-of-activity and bed elevation change across the barred shoreface, relative to the pre-storm surface, are documented in Fig. 12. The values plotted represent the averages of measurements from the two lines of rods 
TABLE 4

Sediment flux determined from depth-of-activity rods

\begin{tabular}{|c|c|c|c|c|}
\hline Date of storm & $I T V F\left(\mathrm{~m}^{3}\right)$ & $I N V F\left(\mathrm{~m}^{3}\right)$ & $\%$ mobilized & $\begin{array}{l}\% \\
\text { change }\end{array}$ \\
\hline 88:06:0I & 55.9 & -11.4 & 4.7 & $\begin{array}{r}-1.0 \\
(-20.0)\end{array}$ \\
\hline 88:06:02 & 28.6 & 2.5 & 2.4 & $\begin{array}{c}0.2 \\
(9.0)\end{array}$ \\
\hline 88:06:03 & 33.2 & -2.7 & 2.8 & $\begin{array}{l}-0.2 \\
(-8.0)\end{array}$ \\
\hline 88:06:05 & 176.2 & 16.4 & 14.8 & $\begin{array}{r}1.4 \\
(9.0)\end{array}$ \\
\hline 88:06:08 & 112.8 & 6.4 & 9.5 & $\begin{array}{c}0.5 \\
(6.0\end{array}$ \\
\hline 88:06:09 & 125.5 & 22.3 & 10.6 & $\begin{array}{r}1.9 \\
(18.0)\end{array}$ \\
\hline 88:06:16 & 101.8 & 22.9 & 8.6 & $\begin{array}{r}1.9 \\
(22.0)\end{array}$ \\
\hline $88: 06: 17-20$ & 106.0 & 9.4 & 8.9 & $\begin{array}{c}0.8 \\
(9.0)\end{array}$ \\
\hline Average & 79.2 & 8.2 & 7.8 & $\begin{array}{c}0.7 \\
(6.0)\end{array}$ \\
\hline
\end{tabular}

Note: $I T V F=$ time-integrated total volume flux; $I N V F=$ time integrated net volume flux.

The $\%$ mobilized and $\%$ change are calculated relative to the control volume. The $\%$ change relative to the volume reactivated is given in parentheses.

deployed 5 and $10 \mathrm{~m}$ north of the instrument line. The maximum depth-of-activity recorded was $0.16 \mathrm{~m}$ and was located closest to the shoreline (10 $\mathrm{m}$ offshore). In general, the depth-of-activity decreased lakewards to a minimum close to zero $230 \mathrm{~m}$ offshore; local re-activation maxima occurred on the bar crests as anticipated $(0.10 \mathrm{~m}$ over the inner bar and 0.07 and $0.09 \mathrm{~m}$, respectively over the second and outer bars). Local minima were associated with the adjacent troughs.

Up to $0.23 \mathrm{~m}$ of accretion was measured on the landward slope of the inner bar (Fig. 12) resulting in a shoreward displacement of the bar form. This shoreward displacement coincided with the lakeward growth of the beach face as a cuspate horn centred on the instrument line (Line 0 ), such that the inner bar became attached to the shoreline by the end of the storm. This accretion process appears to have occurred relatively late in the storm cycle, as the lowest OBS-1P sensor on the first bar crest was buried between $1734 \mathrm{~h}$ and $2104 \mathrm{~h}$.

Up to $0.06 \mathrm{~m}$ of accretion was recorded on both the crest and the upper landward slope of the second bar, while approximately $0.05 \mathrm{~m}$ of sediment was removed from the trough to landward; the result was a small but measurable vertical growth of the bar and a distinct shoreward displacement of the landward slope. This pattern of erosion and accretion over the second bar crest and trough clearly supports the earlier inferences concerning morphodynamics drawn from the sediment flux measurements. No change in bed elevation could be measured across the lakeward slope of the second bar, even though the depth-ofactivity was consistently between 0.06 and $0.08 \mathrm{~m}$. There was no evidence for erosion of the lakeward slope as hypothesized on the basis of the measured sediment flux. The outer bar remained essentially unaltered by the June 16 storm; bed elevation changes were all within the measurement error for the rods of $\pm 0.01 \mathrm{~m}$, even though depths of activity over this feature were at least as large as those measured over the second bar.

These measurements of depth-of-activity and bed elevation change, especially over the two inner 

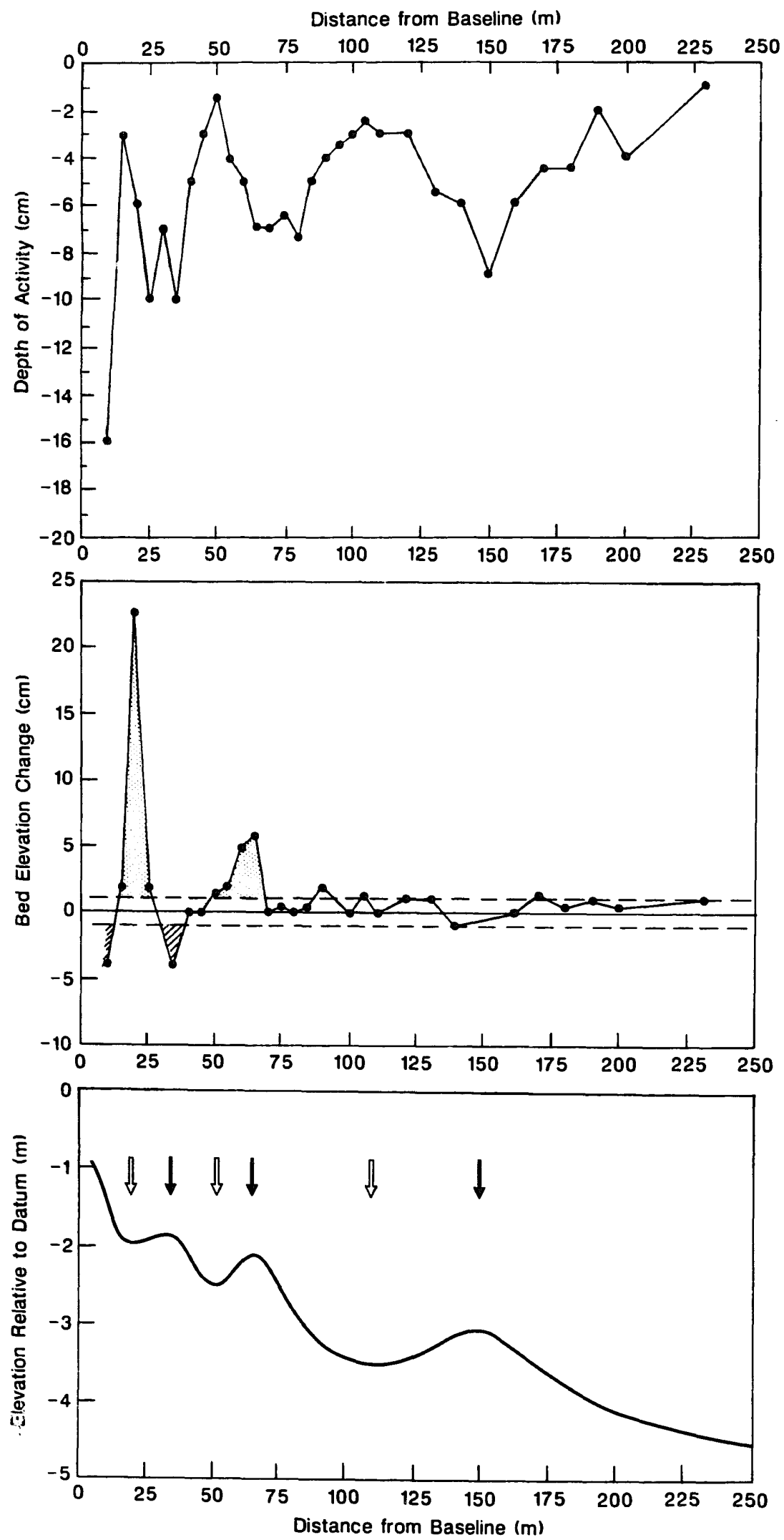
bars, are consistent with previous measurements in this area. For example, Greenwood (1987) reported a simple, inverse linear relationship between depth of re-activation and water depth; local increases and decreases in depth-of-activity were associated, respectively, with the bar crests and troughs. Furthermore, the bar crests experienced sediment accretion while the troughs were eroded; in this way, the bar relief generally increased during storms. Small topographic displacements occurred around average forms such that the bars exhibited a dynamic equilibrium with the prevailing storm-wave climate. The large total time-integrated sediment volume fluxes and the small net volume fluxes measured over several storm events during this study, together with the morphological adjustments recorded during the June 16 storm, would indicate that the Bluewater bars were also in a state of dynamic equilibrium.

\section{Discussion}

Field measurements presented in this paper demonstrate that both the time-averaged (mean) cross-shore current and oscillatory currents at various frequencies are critical in determining the local net suspended sediment transport rate across a barred shoreface. Co-spectral analyses of crossshore velocities and suspended sediment concentrations reveal that grouped, non-linear shoaling waves can induce large onshore sediment transport rates at wind-wave frequencies, while simultaneously producing offshore transport rates at low frequencies. This pattern is essentially similar to that reported earlier for a non-barred shoreface by OG92 (see also Huntley and Hanes, 1987). The propagation of skewed, asymmetric waves in the shoaling zone induces larger onshore velocities within the wave cycle leading to a greater resuspension of sediment and also to a net onshore suspended sediment transport (see also Doering and Bowen, 1989). Outside the surf zone, the resuspension of sediment under groups of large waves is coherent with the offshore phase of a low frequency modulation of the velocity field forced by a group-bound, forced long wave in the manner proposed by Longuet-Higgins and Stewart (1962). The resultant net suspended sediment transport associated with these low frequency oscillations is thus invariably directed offshore, owing to the strong "flux coupling" between the offshore flow associated with the bound long wave (Wells, 1967; Larsen, 1982; Shi and Larsen, i984) and the large sediment concentrations induced by the larger than average waves constituting the wave group (Greenwood and Osborne, 1992; Osborne and Greenwood, 1992b). Furthermore, under certain conditions the group-bound long waves can dominate the net oscillatory component of suspended sediment transport.

It is evident from the analyses presented in this paper that low frequency waves, other than those associated with wave groups, play an important role in suspended sediment transport across a barred shoreface. Landward of the zone of wave breaking on the bar crests and upper lakeward slope, the wave group structure is diminished; nevertheless, a low frequency modulation of the velocity field is still observed and in fact its magnitude, relative to that of the incident frequency, is larger than its counterpart outside the surf zone. This low frequency wave is not, however, coincident in frequency with that of the group-bound, forced long wave in the shoaling zone and may induce significantly larger absolute and net oscillatory suspended sediment transport than that induced by either the shoaling or breaking wind waves. Another difference with the group-forced wave is that a net onshore transport of suspended sediment may result from the "flux coupling" between large sediment concentrations and the onshore phases of these secondary low frequency oscillations. The waves contributing to this low frequency modulation of the velocity field are not defined in this paper, but may be edge waves and/ or reflected long waves (see for example, Bowen

Fig. 12. Elevation, bed-elevation change and depth-of-activity across the upper shoreface. Note: stippling represents accretion and cross-hatching erosion; horizontal dashed lines on the bed elevation change graph represent the measurement error of $\pm 1 \mathrm{~cm}$. Solid circles are rod measurements; solid and open arrows denote location of pre-storm crest and trough, respectively. 
and Huntley, 1984; Kim and Huntley, 1986) in either standing or progressive modes. Previous studies have confirmed the generation of edge waves by storms both in this particular environment (e.g. Bauer and Greenwood, 1990) and elsewhere (e.g. Huntley, 1976; Huntley et al., 1981), but it is clear from other work that leaky long waves are also generated in barred surf zones (e.g. Suhayda, 1974; Katoh, 1984; Wright et al., 1986). Certainly the large magnitudes of suspended sediment transport attributable to the low frequency motions in the surf zone at Bluewater Beach supports the notion that long waves may dominate both the sediment flux and the morphodynamic response under highly energetic conditions (e.g. Holman, 1981; Guza and Thornton, 1982; Bowen and Huntley, 1984).

Under non-linear shoaling and breaking waves the co-spectral signatures were often complex, indicating a constraint upon sediment transport other than the distribution of kinetic energy across frequency space. As waves increased in height to breaking and then subsequently decreased, the oscillatory suspended sediment transport at windwave frequencies showed a marked variation associated with changes in bottom roughness (bt.dforms). Asymmetric vortex ripples were associated consistently with a net onshore oscillatory transport by the wind waves; this transport direction was observed to reverse with increasing wave asymmetry and the onset of post-vortex ripples. Such bedform-sediment transport relationships are consistent with the relatively few laboratory measurements available. Inman and Bowen (1962), for example, indicate that with relatively small asymmetries in the oscillatory velocity field directed in the direction of wave propagation, the net sediment transport was also in this direction. However, as velocity asymmetries favouring the positive phase of wave motion increased, net sediment transport actually decreased and, in one case, reversed. This was a response to the larger sediment concentrations in separation vortices induced by the positive phase of the fluid motion, which, upon ejection from the bed, were in phase with the reversal of the fluid motion. Tanaka and Shuto (1987) demonstrate both theoretically and empiri- cally the existence of an upwave lagrangian fluid motion over steep asymmetric ripples.

More recently, Osborne and Greenwood (1992a) point out that both the regularity with which coherent separation vortices are ejected from the bed and the vertical propagation speed of resuspended sediment will affect correlations between sediment concentration and horizontal velocity at any given elevation and at any given frequency. For example, as oscillatory speeds increase larger volumes of suspended sediment may be carried to higher elevations in the flow by the associated turbulence; a longer time interval for particle settling will therefore be necessary. As a result, sediment may remain in suspension longer and subsequently correlate more effectively with the lower frequency motions.

Across a non-barred shoreface (OG92, their fig. 12), the mean suspended sediment transport rate exhibited a simple, spatially monotonic dependence upon depth as a result of a similar monotonic dependence of both the mean suspended sediment concentration and the mean current (at least offshore of local rip currents). During the small storm monitored at Bluewater Beach, the relative magnitudes of the mean and the net oscillatory components of suspended sediment transport varied through both space and time. At the storm peak when re-suspension of sediment reached a maximum, the time-averaged cross-shore currents (undertows) were critical in determining the local balance of sediment transport, both in terms of magnitude and direction.

The bar topography exerts an important constraint on both the magnitude and direction of transport by the oscillatory and mean currents. Although the bar crest experienced the largest oscillatory currents and greatest levels of turbulence as a result of wave breaking, the net suspended sediment transport rates were minimal, resulting from a near-balance between the mean transport rate directed offshore by undertows and the net onshore oscillatory transport rate controlled by the skewed, asymmetric waves at or close to breaking. Oscillatory transport rates at wind-wave frequencies decreased with increasing water depth both landward and lakeward of the bar crest; here the net oscillatory transport rates 
may be dominated either by long waves or by quasi-steady currents (undertows). Offshore transport across the landward slope will also be constrained by an onshore gravity potential; the converse is true for onshore transport on the lakeward slope, although here the effect should be significantly smaller.

Although only suspended load was monitored in this experiment (and then at only two points in the vertical), the spatial variations in sediment transport do concur with the pattern of accretion, erosion and bar morphodynamics, which resulted from the June 16 storm. Accretion on the crest and upper landward slope of the second bar, coupled with erosion of the trough to landward, caused an increase in topographic relief and a landward migration of the second bar; this pattern of sediment convergence resulted directly from net offshore transport rates in the trough driven by the mean currents (undertows) and near-zero net transport rates across the bar crest. The latter reflect a balance between offshore transport, due to mean currents and group-bound long waves, and onshore transport, induced by the skewed oscillatory velocity field under near-breaking and breaking waves. The large and persistent sediment flux gradient between the near-zero net transport on the bar crest and the net offshore transport on the lower lakeward slope suggested a potential for erosion of the lower lakeward slope. This was not supported by measured bed elevation changes. Since sediment re-activation was significant across the lakeward slope, it is possible that material was indeed removed from the lower lakeward slope during the storm peak and deposited in the outer trougn; this could have been balanced by sediment transported across the bar crest by the mean flow and the downslope component of gravity or by a return of sediment late in the storm, when the lakeward slope was once more dominated by shoaling wind waves.

\section{Conclusions}

Important contributions to the rates of crossshore suspended sediment transport on a barred beach are made by:

(1) a mean transport induced by time-averaged (“quasi-steady") currents exhibiting characteristics of set-up driven undertows;

(2) a net oscillatory transport determined by the interaction of oscillatory currents at wind-wave and low frequencies. Outside the surf zone the latter are a response to the presence of groupbound, forced long waves; inside the surf zone the low frequency modulation is no longer driven by the wave groups, but is secondary in origin and at significantly lower frequencies.

The local net suspended sediment transport rate at any point across a barred shoreface is the resultant sum of the transport vectors attributable to "quasi-steady" currents and the various frequencies of oscillatory motion. A zero net suspended sediment transport rate, resulting in a local sediment mass balance, can therefore be achieved even when individual transport rates may be extremely large. Furthermore. both the relative magnitudes and the directions of the individual suspended sediment transport components vary spatially across the barred profile. In contrast with the non-barred shoreface examined in OG92, where variations followed a simple monotonic pattern with increasing depth across shore, spatial variations in the transport components on the barred shoreface were constrained with respect to position relative to the bar crests. Both the absolute magnitude and the net oscillatory transport of suspended sediment at the incident wave frequency increase landward up the lakeward slope of the bar, with the latter being directed landward as a result of the large skewness and asymmetry in the velocity field induced by the non-linear shoaling waves. These components both decrease shoreward of the bar crest as near-bed oscillatory velocities induced by the wind waves are reduced as a result of dissipation during wave breaking near the bar crest and the propagation landward into increasing water depths over the landward slope and trough. The net oscillatory suspended sediment transport rate induced by low frequency waves increases both landward and lakeward of the breaker zone on the bar crest, as does the mean suspended sediment transport rate. However, while the low frequency motion due to group-bound long waves transports sediment offshore over the shoaling slope as in the case of the non-barred shoreface 
(OG92), the secondary low frequency modulation induced by wave breaking may transport suspended sediment shoreward. Without more detailed information on the structure of the secondary wave however, it is not possible to be definitive in its role in the maintenance of the bar form.

\section{Acknowledgements}

This is a contribution from the Canadian Coastal Sediment Transport Programme (CCOAST) supported by Strategic Grants from the Natural Sciences and Engineering Research Council of Canada to B. Greenwood and A.J. Bowen. P.D. Osborne acknowledges support in the form of a post-graduate scholarship from the same body. We would like to thank R. Brander, J. Ollerhead, N. Sela, and Xu Zhiming from the University of Toronto, and D. Hazen, and S. McLean from Dalhousie University for their assistance in data collection and processing; Dr. David Huntley is to be thanked for fruitful discussion. The support of the Academic Workshops and Graphics Department at the Scarborough Campus of the University of Toronto is also gratefully acknowledged.

\section{References}

Bauer, B.O. and Greenwood, B., 1990. Modification of a linear bar-trough system by a standing edge wave. Mar. Geol., 92: 177-204.

Beach, R.A. and Sternberg, R.W.. 1988. Suspended sediment transport in the surf zone: response to cross-shore infragravity motion. Mar. Geol., 80: 61-79.

Bowen. A.J. and Huntley, D.A., 1984. Waves, long waves and nearshore morphology. Mar. Geol., 60: 1-14.

$D$ and $A$ Instruments and Engineering, 1988. Optical Backscatterance Turbidity Monitor-Instrumentation Manual. $32 \mathrm{pp}$.

Davidson-Arnott, R.G.D. and McDonald, R.A.. 1989. Nearshore water motion and mean flows in a multiple parallel bar system. Mar. Gcol. 86: 321-338.

Dixon. W.J. (Editor), 1985. BMDP Statistical Software, 1985 Printing. Univ. California Press, Berkeley, 734 pp.

Doering. J.C. and Bowen. A.J.. 1989. Wave-induced flow and nearshore suspended sediment. Proc. 21st Coastal Eng. Conf. (Malaga, Spain). Am. Soc. Civ. Eng.. New York. pp. 14521463.

Downing, J.P., Sternberg. R.W. and Lister. C.R.B., 1981. New instrumentation for the investigation of sediment suspension processes in the shallow marine environment. Mar. Geol.. 42: 19-34,

Greenwood. B., 1987. Sediment balance and bar morphody- namics in a multiple bar system: Georgian Bay, Canada. In: V. Gardiner (Editor), International Geomorphology 1986, Part I. Wiley, Chichester, pp. 1119-1143.

Greenwood, B. and Osborne, P.D., 1990. Vertical and horizontal structure in cross-shore flows: an example of undertow and wave set-up on a barred beach. Coastal Eng., 14: 543-580.

Greenwood, B. and Osborne, P.D., 1991. Equilibrium slopes and cross-shore velocity asymmetries in a storm-dominated, barred nearshore system. Mar. Geol., 96: 211-235.

Greenwood, B. and Osborne, P.D., 1992. Wave groups and the re-suspension and transport of sand in the nearshore: 1 . A time series analysis. In: B. Greenwood and E. Mansard (Editors), Wave Groups: Their Role in Nearshore Dynamics and Engineering Design. Assoc. Comm. Shorelines, Natl. Res. Counc. Can., Ottawa, in press.

Greenwood, B. and Sherman, D.J., 1984. Waves, currents, sediment flux and morphological response in a barred nearshore system. Mar. Geol., 60: 31-61.

Greenwood, B. and Sherman, D.J., 1986a. Longshore current profiles and lateral mixing across the surf zone of a barred nearshore. Coastal Eng., 10: 149-168.

Greenwood, B. and Sherman, D.J., 1986b. Hummocky crossstratification in the surf zone: flow parameters and bedding genesis. Sedimentology, 33: 33-45.

Greenwood, B. and Sherman, D.J., 1988. Bedforms and roughness in prototype surf zones. Proc. Workshop on Rughness and Friction. Assoc. Comm. Shorelines, Nat1. Res. Counc. Can., Ottawa, pp. 45-59.

Greenwood, B., Osborne, P.D., Bowen, A.J., Hazen, D.G. and Hay, A.E., 1990. C-Coast: The Canadian Coastal Sediment Transport Programme. Proc. Can. Coastal Conf. (Kingston, Ont.). Natl. Res. Counc. Can., Ottawa, pp. 319-336.

Greenwood, B., Osborne, P.D., Bowen, A.J., Hazen, D.G. and Hay, A.E., 1991a. Nearshore sediment flux and bottom boundary dynamics: The Canadian Coastal Sediment Transport Programme (C-Coast). Proc. 22nd Coastal Eng. Conf. (Delft, The Netherlands). Am. Soc. Civ. Eng., New York, pp. 2227-2240.

Greenwood, B., Osborne, P.D., Bowen, A.J., Hazen, D.G. and Hay, A.E., 1991b. Measurements of suspended sediment transport in prototype shorefaces: the Canadian Coastal Sediment Transport Programme (C-Coast). Proc. Coastal Sediments '9l. (Seattle, Wash.). Am. Soc. Civ. Eng., New York, pp. 284-289.

Guza, R.T. and Thornton, E.B., 1982. Swash oscillations on a natural beach. J. Geophys. Res., 87: 483-491.

Hazen, D.G., Greenwood, B. and Bowen, A.J., 1991. Nearshore current patterns on barred beaches. Proc. 22nd Coastal Eng. Conf. (Delft. The Netherlands). Am. Soc. Civ. Eng., New York, pp. 2061-2072.

Holman, R.A., 1981. Infragravity energy in the surf zone. J. Geophys. Res., 86: 6442-6450.

Huntley, D.A.. 1976. Long period wave motion on a natural beach. J. Geophys. Res., 81: 6441-6449.

Huntley, D.A. and Hanes, D.M., 1987. Direct measurement of suspended sediment transport. Coastal Sediments 78. (New Orleans). Am. Soc. Civ. Eng., New York, pp. 723-737.

Huntley, D.A., Guza, R.T. and Thornton, E.B., 1981. Field 
observations of surf beat: 1. Progressive edge waves. J. Geophys. Res., 86: 6451-6466.

Inman, D.L. and Bowen, A.J., 1962. Flume experiments on sand transport by waves and currents. Proc. 8th Coastal Eng. Conf. Am. Soc. Civ. Eng., New York, pp. 137-150.

Katoh, K., 1984. Multiple longshore bars formed by long period standing waves. Rep. Port Harbour Res. Inst., 23: 3-46.

Kim, C.S. and Huntley, D.A., 1986. On time delays in the nearshore zone between onshore and longshore currents at incidint wave frequencies. J. Geophys Res., 91: 3967-3978.

Larsen, L.H., 1982. A new mechanism for seaward dispersion of mid-shelf sediments. Sedimentology, 29: 279-284.

Longuet-Higgins, M.S. and Stewart, R.W., 1962. Radiation stress and mass transport in gravity waves, with application to "surf beats". J. Fluid Mech., 13: 481-504.

Nielsen, P., 1984. Field measurements of time-averaged suspended sediment concentrations under waves. Coastal Eng., 8: 51-72.

Ollerhead, J., 1989. Bedform geometry and dyamics during storms in a barred nearshore zone, Bluewater Beach, Ontario, Canada. M.Sc. Thesis, Univ. Toronto, 173 ps. (Unpubl.).

Ollerhead, J. and Greenwood, B., 1990. Bedform geometry and dynamics in the upper shoreface, Bluewater Beach, Ontario, Canada. Proc. Can. Coastal Conf. (Kingston, Ont.). Assoc. Comm. Shorelines, Natl. Res. Counc. Can., Ottawa, pp. 337-348.

Osborne, P.D. and Greenwood, B., 1991. Set-up driven undertows on a barred beach. Proc. 22nd Coastal Eng. Conf. (Delft, The Netherlands). Am. Soc. Civ. Eng., New York, pp. 227-240.

Osborne, P.D. and Greenwood, B., 1992a. Sediment suspension under waves and currents: time scales and vertical structure. Sedimentology, (submitted).

Osborne, P.D. and Greenwood, B., 1992b. Wave groups and the re-suspension and transport of sand in the nearshore: 2 . A spectral analysis. In: B. Greenwood and E. Mansard (Editors), Wave Groups: Their Role in Nearshore Dynamics and Engineering Design. Assoc. Comm. Shorelines, Natl. Res. Counc. Can., Ottawa, in press.

Osborne, P.D. and Greenwood, B., 1992c. Frequency dependent cross-shore suspended sediment transport. 1. A nonbarred shoreface. Mar. Geol., 106: 1-24.

Osborne, P.D., Greenwood, B. and Bowen, A.J., 1990. Crossshore suspended sediment transport on a non-barred beach: the role of wind waves, infragravity waves and mean flows. Proc. Can. Coastal. Conf. (Kingston). Natl. Res. Counc. Can., Assoc. Comm. Shorelines, pp. 349-361.

Shi, N.C. and Larsen, L.H., 1984. Reverse sediment transport induced by amplitude modulated waves. Mar. Geol., 60: 199-218.

Suhayda, J.N., 1974. Standing waves on beaches. J. Geophys. Res., 79: 3065-3071.

Symonds, G. and Bowen, A.J., 1984. Interactions of nearshore bars with incoming wave groups. J. Geophys. Res., 89: 19531959.

Tanaka, H. and Shuto, N., 1987. Velocity measurements of wave-current combined motion over an asymmetric rippled bed. Coastal Sediments '87. (New Orleans). Am. Soc. Civ. Eng., New York, pp. 379-392.

Thornton, E.B., Galvin, J.J., Bub, F.L. and Richardson, D.P., 1977. Kinematics of breaking waves. Proc. 15th Coastal Eng. Conf. (Honolulu). Am. Soc. Civ. Eng., New York, pp. 461-476.

Wells, D.R., 1967. Beach equilibrium and second order wave theory. J. Geophys. Res., 72: 497-504.

Wright, L.D., Nielsen, P., Shi, N.C. and List, J.H., 1986. Morphodynamics of a bar-trough surf zone. Mar. Geol., 70: 251-285. 